Faculty of Arts and Sciences, FiF-thesis 117

\title{
The Investment Process for Capital Investments \\ - The case of industrial energy-efficiency investments and non-energy benefits
}

\author{
Josefine Rasmussen
}

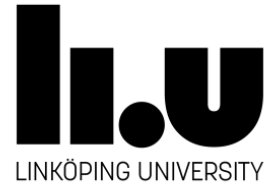

2016

Department of Management and Engineering

Linköpings universitet

SE-581 83 Linköping, Sweden 
(C) Josefine Rasmussen, 2016

Filosofiska fakulteten, FiF-avhandling 117

ISBN: 978-91-7685-790-8

ISSN: 1401-4637

Printed by: LiU-Tryck, Linköping

Distributed by:

Linköpings universitet

Department of Management and Engineering

SE-581 83 Linköping, Sweden

Tel: +13-281000, fax: +13-281101 


\begin{abstract}
Capital investments play a crucial role for the business of every firm. In an industrial context, energy efficiency is an important means to meet future energy needs and in the same time reduce climate impact. In this thesis, the investment process for capital investments is therefore studied by addressing the case of industrial capital investments improving energy efficiency. The thesis specifically aims to illuminate how additional benefits, i.e. non-energy benefits, are and can be acknowledged in the investment process by applying an ex-ante perspective. The thesis holds the decision-making process as unit of analysis and aims to contribute with insights on firm level. Especially in an energy-efficiency context, such a process perspective has only been scarcely applied.
\end{abstract}

The thesis is based on a literature review and two empirical studies. The literature review is the starting point of the thesis and reviews the literature on benefit concepts and investment behaviour of energy-efficiency investments. It is then followed by an explorative study in which thirteen industrial Swedish firms are interviewed on how they consider non-energy benefits. Investment motives and critical aspects for adopting energy-efficiency investments are also addressed. It also includes a questionnaire, distributed and collected during a networking event for energy-intensive firms within Swedish manufacturing industry. The second empirical study is a case study conducted at a Swedish pulp and paper firm. It aims to take a comprehensive perspective on the investment process as well as to analyse how and when non-energy benefits are acknowledged in the investment process. This case study approach enables participants at different levels in the organisation to be engaged in the study and new perspectives to be addressed.

The results indicate a general investment process passing through the phases identification, development and selection. Investment motives, information, internal coordination and external actors appear as key aspects of the investment process. Energy-efficiency investments are primarily initiated due to cost-savings motives. However, the subsequent investment process appears as consistent for all investment categories; the investment process described here is thus not specific for energy-efficiency investments only. The results instead indicate an investment process influenced by investment size; it influences the extent to which information is collected and assessed before making the decision, i.e. level of procedural rationality, as well as how the investment project is coordinated within the firm. Last, suppliers are involved in the investment process to a large extent from an early stage.

Regarding non-energy benefits, the results indicate that various benefits have been observed but far from all are acknowledged in the investment process. They are to a larger extent acknowledged for larger investments when more resources are devoted to the investment process. Quantifiable non-energy benefits improve the business case for energy-efficiency investments and non-energy benefits should thus be quantified to the extent possible. Yet, nonenergy benefits characterised by a lower level of quantifiability could still be important, such as benefits related to work environment, and should therefore be considered. However, the findings indicate a frequent use and reliance upon an investment manual, implicating a need for simplicity when addressing the additional benefits. This indicates that there should be an emphasis on a limited number of main benefits, rather than seeking to acknowledge all possible benefits.

Keywords: Investment process, investment decision making, capital investments, energy efficiency investments, non-energy benefits, industry. 


\section{Acknowledgements}

If someone would have told the undergraduate me, writing a master thesis in economics, that I would "change side" and become a PhD student in business administration, I probably would not have believed them. Today, halfway through, I am very grateful that I was given the opportunity and that I took the chance. There are several people that I want to thank for making this licentiate thesis possible.

First of all, I wish to thank my supervisors for giving me the opportunity in the first place and for all the support along the way. Mikael Ottosson and Henrik Nehler, thank you for your guidance and the encouraging discussions, always pushing me to go further. Fredrik Tell, thank you for your comments and constructive feedback at the pre-final seminar, which truly helped to improve the thesis.

Both empirical studies in this thesis have been conducted together with my research colleague Therese Nehler. Thank you for the close and good collaboration! I have really appreciated our work together, in doing fieldwork and especially in writing Paper II.

I also wish to thank Patrik Thollander. Thank you for your valuable input, comments and positive spirit.

To everyone at the participating firms who gave freely of their time being interviewed and answering the questionnaire - thank you! In particular, I wish to express my sincere thanks to everyone at $\mathrm{P} \& \mathrm{P}$ for participating in the case study.

None of this would have been possible without financial support and I therefore wish to express my gratitude to the Swedish Energy Agency and the Department for Management and Engineering at Linköping University for funding this research.

I also want to thank my colleagues at Business Administration and especially my fellow PhD students: Svjetlana, Jenny, Hugo, Linus, Christopher, Victor, David, Aliaksei, Anja, Johanna, Vivi, Mehdi and Susan. Thank you for your support and all the good discussions on seminars and courses, but mostly, thank you for all the laughs and fun talks during lunches, after works and the mandatory fika breaks!

During my time as a PhD student so far, I have belonged to the IEI Research School. This has given me the opportunity to get to know PhD students at other divisions and from other disciplines, which I have really appreciated. Thank you also for all the fruitful discussions during our workshops, seminars and courses.

However, I would not be here if it was not for my family. To my parents Gunilla and Johan, and my sisters Malin, Sofie and Julia: Thank you for your love and support. You are the best!

Finally, thank you Petter for always listening, being supportive and for your patience, especially during the last few months. Thank you for your love, for always being there and encouraging me.

Josefine Rasmussen

Linköping, March 2016 


\section{Appended papers}

\section{Paper I}

Rasmussen, J. (2015). Towards a broader view on energy-efficiency investments: An integrative review on benefit concepts and investment behaviour. Under review for journal publication.

Previous version presented at the ECEEE Industrial Summer Study in Arnhem 2014 and published in the conference proceedings: Rasmussen, J. (2014). Energy-efficiency investments and the concepts of non-energy benefits and investment behaviour. Proceedings ECEEE Industrial Summer Study - Retool for a Competitive and Sustainable Industry, 733-744.

\section{Paper II}

Nehler, T. and Rasmussen J. (2016). How do firms consider non-energy benefits? Empirical findings on energy-efficiency investments in Swedish industry. Journal of Cleaner Production 113: 472-482.

\section{Paper III}

Rasmussen, J. (2016). How to acknowledge non-energy benefits? A case study approach on the investment process for energy-efficiency investments. Working paper. 


\section{Table of contents}

\section{Part I: Synthesis}

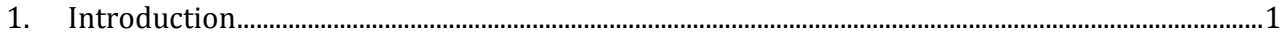

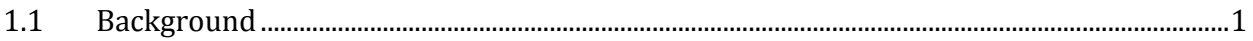

1.2 Setting the empirical context: Investments as a means to improve industrial energy

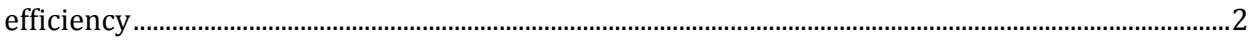

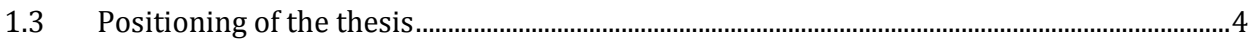

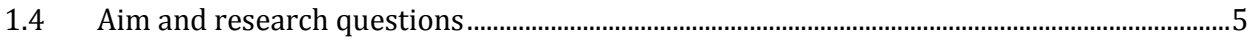

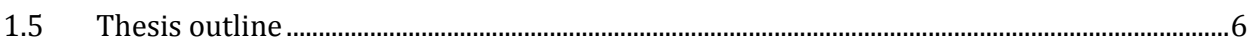

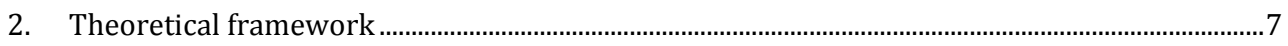

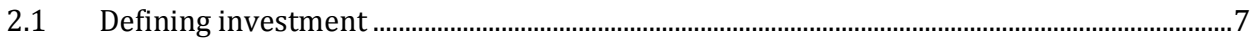

2.1.1 Capital investments improving energy efficiency ...............................................................

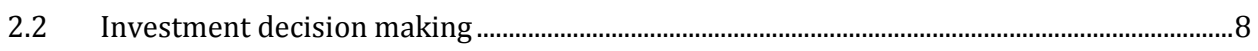

2.2.1 A comprehensive take on the investment process......................................................10

2.3 The additional benefits of energy-efficiency investments....................................................12

$2.4 \quad$ Energy-efficiency gap................................................................................................................. 13

2.5 Previous research on investments improving energy efficiency.........................................13

2.5.1 Strategic character of capital investments .................................................................... 14

2.5.2 Barriers and driving forces to energy efficiency.............................................................. 15

2.6 How the theoretical framework is applied in the thesis ........................................................ 16

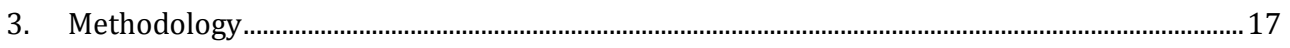

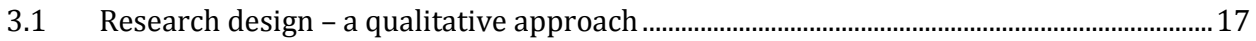

3.1.1 An interdisciplinary approach ........................................................................................... 19

3.1.2 The role of theory.......................................................................................................19

3.1.3 Externally funded research project and academic freedom .........................................20

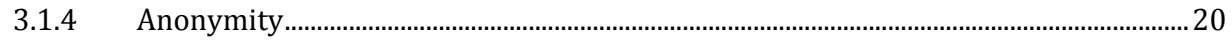

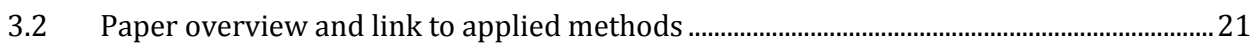

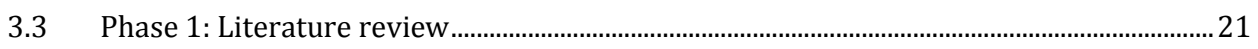

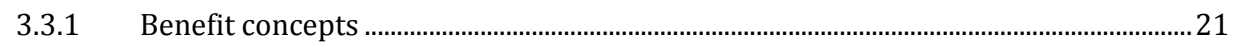

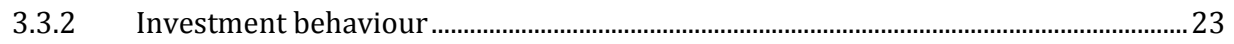

3.3.3 Analysis and implications for the subsequent research process .................................24

3.3.4 My contribution ............................................................................................................ 24

3.4 Phase 2: Exploration through a qualitative approach ............................................................24

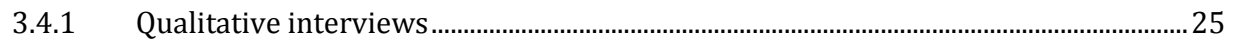

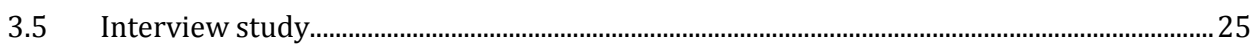

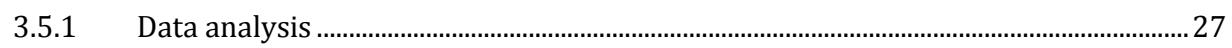

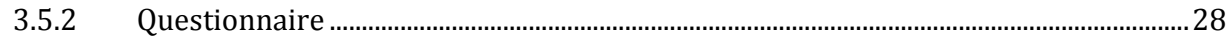

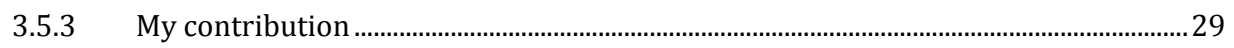




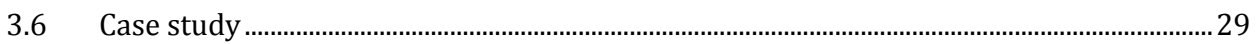

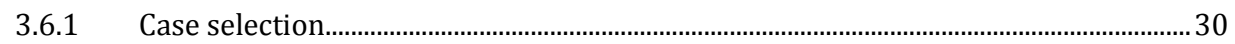

3.6.2 The case firm ............................................................................................................... 30

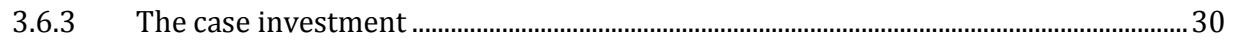

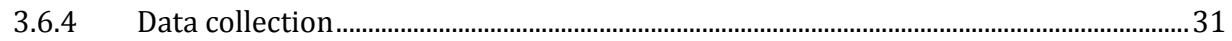

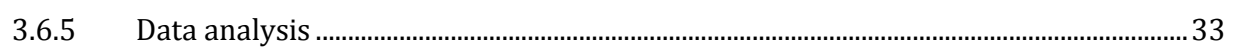

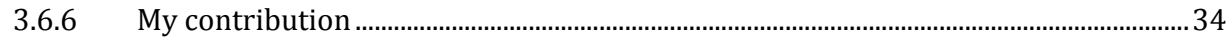

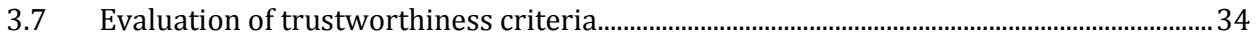

4. Summary of papers.............................................................................................................................37

4.1 Paper I: Towards a broader view on energy-efficiency investments: An integrative review on benefit concepts and investment behaviour

4.2 Paper II: How do firms consider non-energy benefits? Empirical findings on energyefficiency investments in Swedish industry.......................................................................................38

4.3 Paper III: How to acknowledge non-energy benefits? A case study approach on the investment process for energy-efficiency investments.......................................................................39

4.4 Linking main findings to paper overview............................................................................ 40

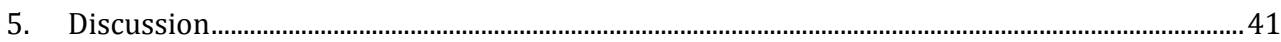

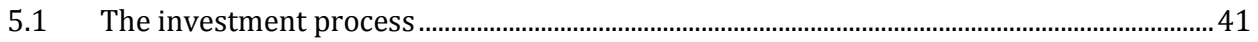

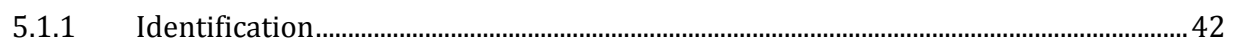

5.1.2 Development and selection......................................................................................... 42

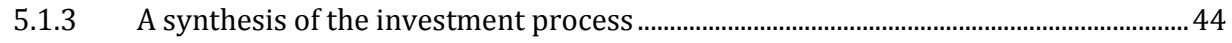

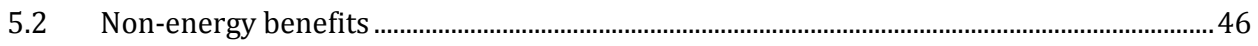

5.2.1 To what extent are non-energy benefits acknowledged? ............................................... 46

5.2.2 How should non-energy benefits be defined and acknowledged? ................................ 47

5.3 Combinatorial energy-efficiency investments and non-energy benefits - a remark .......50

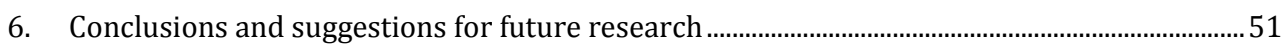

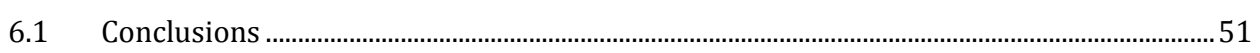

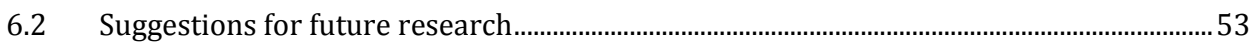

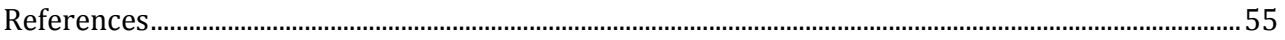




\section{List of figures}

Figure 1. An illustration of the two phases in the research process.

Figure 2. Flow diagram of the search and selection processes for the three benefit concepts......23

Figure 3. The phases and key aspects of the investment process .45

\section{List of tables}

Table 1. Overview of the papers' connection to the research aim and questions.

Table 2. Characterisation framework of energy-efficiency investments with selected attributes

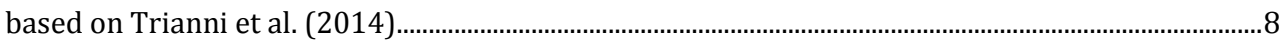

Table 3. Paper overview and connection to research aim and theoretical framework....................16

Table 4. Paper overview and link to research aim, theoretical framing and methods used............21

Table 5. Description of systematic literature search..............................................................................22

Table 6. Firm characteristics of the interviewed firms. ..........................................................................26

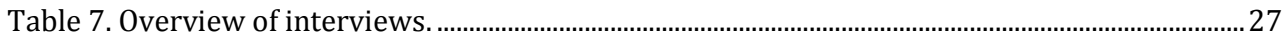

Table 8. Questionnaire questions and response rates..............................................................................28

Table 9. Overview of interviews in the case study................................................................................

Table 10. The aspects covered in the interview guide by theme. ............................................................32

Table 12. Paper overview and link to research aim, theoretical framing, methods applied and main findings.

Table 13. Suggestions on how to define and acknowledge non-energy benefits in the investment process. 49

\section{Part II: Appended papers}

Paper I: Towards a broader view on energy-efficiency investments: An integrative review on benefit concepts and investment behaviour.

Paper II: How do firms consider non-energy benefits? Empirical findings on energy-efficiency investments in Swedish industry.

Paper III: How to acknowledge non-energy benefits? A case study approach on the investment process for energy-efficiency investments. 


\section{Part I:}

Synthesis 



\title{
1. Introduction
}

\author{
"Capital investment decisions rank among the most critical types \\ of managerial decisions made in a firm."
}

(Maritan 2001, p. 513)

The above quote sets off a previous article of capital investment decision making in a manufacturing firm (Maritan 2001). A basic definition of a capital investment is an investment in a real asset that is expected to generate a future return (Brealey et al. 2011). For a firm, this can for instance be an investment aiming to increase capacity, improve product quality or contribute to a more efficient utilisation of resources. The importance of capital investments is further stressed by Lumijärvi (1991, p. 171): "Investments affect operations and cash flows of firms for long period of time, making investment success extremely important". Capital investment decisions are also stated as an important means for implementing strategies (Grundy and Johnson 1993) and ensuring performance (Emmanuel et al. 2010). Making investment decisions is a matter of making decisions on resource allocation (Bower 1986) and previous research has indicated that firms having so-called "more room for financial manoeuvring", i.e. more available resources, have a less formal investment decision-making process (Van Cauwenbergh et al. 1996, p. 175). However, since firms generally have limited available resources, making allocation decisions, such as investment decisions, is fundamental (Lumijärvi 1991). The question is then, how do firms make these important investment decisions? This will be the subject of this thesis.

\subsection{Background}

"We believe that, in order to understand contemporary economic decision making, we need to supplement the study of market factors with an examination of the internal operation of the firm [...]. Its major functions are performed by different divisions more or less coordinated by a set of control procedures. [...] Within the firm, information is generated and processed, decisions are made, results are evaluated, and procedures are changed."

(Cyert and March 1963, p. 1)

Making an investment decision is a continuous process, as first developed by Cyert and March (1963). However, studies on capital investment decisions generally place emphasis on the financial evaluation of investments, such as capital budgeting tools and practices (e.g. Bennouna et al. 2010; Graham and Harvey 2001; Lefley 1996; Sandahl and Sjögren 2003; Qiu et al. 2015). Although financial evaluation plays an important role in investment decision making (Van Cauwenbergh et al. 1996), it is only one step of the process (King 1975) and "corporate investment behaviour is considerably more complex than can be described by the bare-bones NPV model of investment" (DeCanio and Watkins 1998, p. 105). This complexity may stem from the characteristics of the investment; capital investments can vary in nature and may yield both tangible and intangible benefits. For capital investments in IT/IS, Irani and Love (2002) suggest 
that different benefits can be represented on different planning levels: on the tactical and operational levels benefits are often tangible and financial in nature, whereas benefits on a strategic level often are of an intangible and non-financial character. Grundy and Johnson (1993) indicate that for major investments, intangible benefits may be tangible in a long-term perspective. In a study in investments in new technologies, it has therefore been suggested that these benefits should be identified in the investment appraisal, even though they are difficult to assess through traditional evaluation models (Ashford et al. 1988).

Mintzberg et al. (1976) maintained the view of decision making as a process. By studying 25 strategic decision processes, a basic model was developed in which three phases are defined: identification, development and selection. Upon selection, an investment may require authorisation by senior management (Mintzberg et al. 1976). Selling the investment project to senior management such as the internal board (Lumijärvi 1991) and seeking consensus (Emmanuel et al. 2010) have in turn been identified as important aspects of the investment process. However, the involvement by senior management differs for different types of investments (Maritan 2001) and they may only play a coordinating role (Segelod 1996). Investment analysis could therefore work as both a decision-making and a communication instrument (Van Cauwenbergh et al. 1996). Hence, the decision-making process takes place through a number of steps (e.g. Maritan 2001; Mintzberg et al. 1976; Nutt 1993) and is influenced by for instance the different actors involved during this process (Xue et al. 2008). Thus, only studying one step will give limited insights on how decisions on capital investments are made; for example, only focusing on the evaluation step will not provide any insights on influential preceding steps, as pointed out by King (1975). This suggests that the decisionmaking process is the adequate unit of analysis for studying how capital investment decisions are made.

\subsection{Setting the empirical context: Investments as a means to improve industrial energy efficiency}

\section{"Industrial energy efficiency is a key foundation for greener industry worldwide."} (UNIDO 2011, p.1)

The industrial sector accounts for almost 40 per cent of the final energy use in Sweden (SEA 2012) and one-third globally (IEA 2014a). Energy is an important input for every firm to ensure basic necessities such as heating and lighting. For an industrial firm, it is also an important input in production (SEA 2015). In order to meet future needs in energy demand, there is an increasing need to improve energy efficiency, as implied by the above quote. According to the International Energy Agency, the global cumulative investment need in energy efficiency until 2035 amounts up to 48 trillion US dollars (IEA 2014b). One way to reduce energy use is by undertaking efforts in energy efficiency, of which one such effort is investments. Investments improving energy efficiency are investments that enable the same level of output to a lower level of energy input (e.g. IEA 2012).

Despite the rising need for increasing energy efficiency, there is an untapped potential of energy efficiency, i.e. a gap between the actual and optimal level of energy efficiency, even though cost effective energy-efficient technologies are available. This gap is referred to as the energyefficiency gap (e.g. Hirst and Brown 1990). The energy-efficiency gap is a well-known paradox within the energy community with several attempts to explain and propose ways to overcome this gap (e.g. DeCanio 1998, 1993; Jaffe and Stavins 1994a). Proposed explanations have been for instance market and non-market failures as well as firm and investment characteristics. The energy-efficiency gap was recently quantified in Sweden and approximately 60 per cent of the potential was estimated to be accountable from energy-efficient technologies, i.e. investments, corresponding to $577 \mathrm{GWh} /$ year (Paramonova et al. 2015). To overcome the market failures 
hindering energy-efficiency improvements, a number of policies and programmes have been implemented, of which one Swedish example is the Programme for Energy Efficiency (PFE${ }^{1}$ ) (SEA 2014a). However, overcoming market failures may not be sufficient to close the energyefficiency gap. Barriers within firms to energy efficiency have been addressed since "the firm is shaped by internal informational and incentive factors having little to do with the neoclassical paradigm" (DeCanio 1993, p. 912).

Previous research on investment decision making for investments improving energy efficiency has studied the barriers and driving forces to adoption (e.g. Brunke et al. 2014; Rohdin et al. 2007; Trianni et al. 2013). A study on the Swedish pulp and paper industry concluded that both behavioural and organisational related barriers and driving forces are ranked high, including barriers such as lack of budget funding, other priorities for capital investments and long decision chains, and driving forces such as people with real ambition and having a long-term energy strategy (Thollander and Ottosson 2008). Barriers identified in other studies are for instance a low priority level, more important investment opportunities, lack of management time, lack of access to capital, slow rate of return and a focus on daily production activities, among others (De Groot et al. 2001; Sardianou 2008; Venmans 2014). Not being linked to core business is another suggested reason for why investments in energy efficiency may lack priority against other investments (Cooremans 2012, 2011). In light of the identified organisational and behavioural barriers and the presence of an energy-efficiency gap, there is a need to go within the firm to study how and on what basis firms make investment decisions for investments improving energy efficiency. Therefore, this thesis will address investment decision making for capital investments and specifically capital investments improving industrial energy efficiency.

Returning to the decision-making model suggested by Mintzberg et al. (1976), the selection phase in addition to authorisation includes evaluation, which for instance takes place by applying capital budgeting tools. The evaluation criteria applied for energy-efficiency investments have also been studied in an energy efficiency context, indicating a frequent use of net present value (NPV) and especially the payback method (PB) for energy-efficiency investments (e.g. Cooremans 2012; Harris et al. 2000). Requirements of a PB period of three years or less have been indicated for Swedish industry (Thollander and Ottosson 2010). However, even though it could contribute to an improved NPV or a shorter PB time, not all benefits related to a capital investment are acknowledged in the investment process (Ashford et al. 1988). The issue of not considering all benefits has been acknowledged in the context of energy-efficiency improving investments as well (e.g. Pye and McKane 2000).

\section{"A multiple benefits approach adds value to energy efficiency."}

(IEA 2014a, p. 33).

Investing in energy efficiency can amount to more than meeting future energy demand and be beneficial for society as well as the individual firm (IEA 2014a, 2012; UNIDO 2011). For society, improved energy efficiency can for instance also contribute to health and social benefits (e.g. IEA 2012). On firm level, a positive and significant relationship between climate friendly management practices, including adopting energy-efficient technologies, and higher productivity has been indicated (Martin et al. 2012). It has further been argued that increased efficiency and a more productive use of resources will lead to improved competitiveness (Porter and van der Linde 1995) and that firms voluntarily undertaking sustainability policies, so-called 'High Sustainability' firms, show better long-term performance, compared to so-called 'Low Sustainability' firms (Eccles et al. 2014).

\footnotetext{
${ }^{1} \mathrm{PFE}$ is a voluntary long term agreement governed by the Swedish Energy Agency. The programme aims to improve energy efficiency in the manufacturing industry by giving participating firms a tax credit. The participating firms are obligated to perform energy audits, energy analyses, and implement proposed energy-efficiency investments and measures with a PB period of less than 3 years. The programme will end during 2017 (SEA 2014a).
} 
There are different benefit concepts in the literature, such as multiple benefits, co-benefits and non-energy benefits (see for example IEA 2012 who applies the term 'multiple benefits'). However, no clear definitions or distinctions between these benefit concepts are present in the literature today. These additional benefits vary in nature and can for example include increased productivity, reduced production costs, improved product quality, improved public image or improved worker safety, i.e. they represent the additional benefits beyond energy cost savings (e.g. Pye and McKane 2000). Including these additional benefits in the investment evaluation has been found to lead to shorter PB periods for energy-efficiency investments (Lung et al. 2005; Worrell et al. 2003) and the additional benefits may also be larger than the actual energy cost savings (Pye and McKane 2000). Not including all benefits in the evaluation of energy-related investments thus leads to an underestimation of their potential (e.g. Worrell et al. 2003). Moreover, investments improving energy efficiency can have different motives and drivers, both energy related such as potential energy-cost savings (e.g. De Groot et al. 2001; Thollander and Ottosson 2008) and not energy related such as improving productivity; i.e., the additional benefits can motivate an energy-efficiency investment (Pye and McKane 2000). Investment motive and categorisation have in turn been identified as determinants for the subsequent process (Cooremans 2012).

\subsection{Positioning of the thesis}

Both the IEA and the UN have addressed the potential of multiple benefits (IEA 2014a, 2012; Puig and Farrell 2015) but previous research is scarce on these additional benefits of energy efficiency. A limited number of studies have acknowledged them and stressed their importance for industrial energy efficiency (e.g. Boyd and Pang 2000; Mills et al. 2008; Pye and McKane 2000; Worrell et al. 2003). However, previous research tend to in general apply an ex-post perspective and less is therefore known on the extent to which firms consider the additional benefits during the investment process. Pye and McKane (2000, p. 182) described non-energy benefits as a means to make a business case of energy efficiency:

"Since businesses make most decisions based on bottom-line impact, it makes sense to look at energy efficiency as part of overall 'efficiency' (e.g. process efficiency, enhanced productivity) to account for all the savings that a business will realise from energy efficiency projects. In order to make a more compelling case for energy efficiency and pollution prevention, it is critical to understand the decision-making process of business management."

Considering energy efficiency as part of overall efficiency is in line with the view taken in this thesis. Investments improving energy efficiency are in the literature addressed as energyefficiency investments. However, in industry it may be difficult to separate an investment in energy efficiency from an investment in production or support processes since these often are connected (Thollander and Ottosson 2010). Even if the main aim of the investment is for instance production related, it may still improve energy efficiency and thus be an energyefficiency investment, as argued by Fleiter et al. (2012). Energy-efficiency investments should therefore be considered as any other capital investment with the additional value that it improves energy efficiency. This perspective places further emphasis on acknowledging other benefits in addition to energy cost savings when investments related to improved energy efficiency are concerned.

Quantifying the additional benefits by translating them into monetary values have been suggested as a means to show the financial possibilities of energy-efficiency investments and increase the probability of adopting them (Pye and McKane 2000). As expressed by UNIDO, energy-efficiency investments "entail estimating the size and the timing of a project's income and outlays and choosing among investment options" (2011, p. 68). On the other hand, there are findings suggesting that financial evaluation only is one part of the process (King 1975) and that other factors are of higher importance for achieving investment approval, especially factors of a strategic character (Cooremans 2012, 2011). Arguments for promoting an investment may in 
turn be economic, non-economic, strategic or related to production technology (Lumijärvi 1991). Despite the nature of the benefits, they should be accounted for in the investment process (Ashford et al. 1988). Therefore, it should be of utmost importance to also acknowledge the additional benefits during the investment process.

Dean and Sharfman (1993a) differ between the process-oriented approach to decision making and the choice-based approach, of which the latter is focused on why choices are made. The energy-efficiency literature has to a large extent had a choice-based approach through the emphasis on barriers and driving forces (e.g. Brunke et al. 2014; Rohdin et al. 2007; Trianni et al. 2013) or mostly been limited to one phase of the process: selection and the applied evaluation criteria, such as PB thresholds (e.g. Harris et al. 2000; Thollander and Ottosson 2008). Cooremans (2012) is to the author's best knowledge the only study in which a comprehensive perspective is taken on the decision-making process. Cooremans (2012) provides an important contribution, yet the study was based on a small sample of firms supervising buildings and industrial sites in the secondary and tertiary sectors. The studied firms ranged from being active in for example the chemical industry to chain stores and shopping malls, and therefore differed in a number of characteristics. Thus, additional research on this subject is needed. In light of the advocated process perspective (e.g. Cyert and March 1963; King 1975; Mintzberg et al. 1976) and the persisting energy-efficiency gap (Paramanova et al. 2015), there is therefore a need for further research on energy-efficiency improving investments with a comprehensive take on the investment process.

The thesis holds the view that making energy-efficiency investment goes beyond the scope of solely improving energy efficiency. Since the motives behind energy-efficiency investments may vary, so may also the information taken into account during the process, including both energy related information, such as energy cost savings, and non-energy related information, i.e. additional benefits. To explore how and the extent to which additional benefits are acknowledged when firms make investment decisions on energy-efficiency investments, what information and the extent to which it is acknowledged should be addressed. Moreover, the thesis considers decision making as a process, which in turn is not restricted to a sequence of steps but affected by different factors as well, such as the actors involved, information addressed or how investments are authorised. For industrial energy-efficiency improving investments, such a process perspective on the investment process can add new insights on how these investments decisions are made and how additional benefits are acknowledged. Consequently, it could also contribute to closing the energy-efficiency gap. In light of the preceding discussion, the aim and research questions of the thesis are stated below.

\subsection{Aim and research questions}

The aim of the thesis is to add insights on firms' investment decision making for capital investments by addressing the case of capital investments improving energy efficiency in industry. The thesis places particular emphasis on the varying nature of investment benefits by illuminating how additional benefits are and can be acknowledged during the investment process. The aim will be addressed through three research questions:

1. What characterises the investment process for energy-efficiency investments?

2. To what extent do firms acknowledge additional benefits when making investment decisions on investments improving energy efficiency?

3. How should additional benefits be:

a. Defined in an industrial context?

b. Acknowledged in the investment process?

The thesis aims to contribute with insights on a firm level by having the decision-making process as the unit of analysis. The investment process is in the thesis not delimited to the steps of the 
process or the evaluation methods used during analysis, but surrounding aspects such as motives, involved actors and information are also accounted for.

\subsection{Thesis outline}

The thesis is comprised by three papers, appended in Part 2, and a synthesis of these papers, presented in Part I. The remainder of Part I is organised as follows. Chapter 2 presents the theoretical framework of the thesis. The methods used and the methodological approach of the thesis are described in chapter 3. Chapter 4 summarises the results of the three papers, which is followed by a discussion in chapter 5. Finally, the conclusions and implications for future research are discussed in chapter 6 .

In Part II, the three papers are appended. All papers are connected to the general aim of the thesis but through different methodological approaches. An overview of the appended papers is displayed in Table 1.

Table 1. Overview of the papers' connection to the research aim and questions.

\begin{tabular}{ll}
\hline Paper & $\begin{array}{l}\text { Link to aim and research } \\
\text { questions }\end{array}$ \\
\hline Paper I & General aim, RQ1 and RQ3. \\
Paper II & $\begin{array}{l}\text { General aim, RQ2 and RQ3. } \\
\text { (RQ1). }\end{array}$ \\
Paper III & $\begin{array}{l}\text { General aim, RQ1, RQ2 and } \\
\text { RQ3. }\end{array}$ \\
\hline
\end{tabular}

The first paper is a literature review which addresses the first and third research questions. The second paper is an explorative study addressing all three research questions but with its main emphasis on the last two. The third paper is a case study addressing all three research questions. 


\section{Theoretical framework}

In this chapter, the theoretical framework for the thesis is presented. It starts with a definition of investments and investments improving energy efficiency. It is then followed by investment decision making. The section on additional benefits then serves as a bridge to the sections on energy-efficiency improving investments starting with the energy-efficiency gap. Finally, previous research on energy-efficiency investments, including barriers and driving forces, is covered.

\subsection{Defining investment}

In the introduction, a capital investment was defined as an investment in a real asset expected to generate some future return (Brealey et al. 2011). Bierman and Smidt (2012, p. 3) provides a similar definition: "commitments of resources made in the hope of realising benefits that are expected to occur in future periods" and Emmanuel et al. (2010) mention for instance investments in new facilities or new technology. This thesis follows these definitions of a capital investment and capital investment decisions as resource allocation decisions. The investment process is in turn the decision-making process in which these decisions are made (e.g. Bower 1986).

\subsubsection{Capital investments improving energy efficiency}

In this thesis, capital investments improving energy efficiency are specifically studied. For these investments, the return may stem from energy cost savings or cost savings and revenues from other effects, as indicated in previous frameworks (Fleiter et al. 2012; Trianni et al. 2014). These additional benefits can include for example reduced maintenance costs or improved productivity and are addressed in section 2.3. However, the 'return' will in most cases arise from avoided or decreased costs (Bunse et al. 2009).

The energy using units at an industrial firm can be divided into production processes or support processes (Söderström 1996). Capital investments improving energy-efficiency can thus be related to either category and Fleiter et al. (2012) have proposed a framework for characterising energy-efficiency improving investments ${ }^{2}$. Through the framework, the investments can be classified according to three classes of characteristics. The first class is relative advantage, which includes expenditure, internal rate of return (IRR), payback period (PB) and non-energy benefits. The second class technical context includes core process, modification type, scope of impact and lifetime, and the third class information context includes transaction costs, knowledge for planning and implementation, diffusion progress and sectoral applicability (Fleiter et al. 2012).

2 Fleiter et al. (2012), along with others, use the term 'energy-efficiency measures'. Energy-efficiency measures can include both investments and operational measures not requiring an investment cost. In this thesis, the term 'energyefficiency investments' is therefore used to avoid confusion. 
Trianni et al. (2014) characterise energy-efficiency improving investments by six categories of attributes, which are economic, environmental or related to energy, production, implementation or interaction. These categories are displayed in Table 2 below, along with selected attributes ${ }^{3}$.

Table 2. Characterisation framework of energy-efficiency investments with selected attributes based on Trianni et al. (2014).

\begin{tabular}{|c|c|c|c|c|c|}
\hline Economic & $\begin{array}{l}\text { Energy- } \\
\text { related }\end{array}$ & $\begin{array}{l}\text { Environ- } \\
\text { mental }\end{array}$ & $\begin{array}{l}\text { Production- } \\
\text { related }\end{array}$ & $\begin{array}{l}\text { Implementation } \\
\text {-related }\end{array}$ & $\begin{array}{l}\text { Interaction } \\
\text {-related }\end{array}$ \\
\hline $\begin{array}{l}\text { PB } \\
\text { Implementation } \\
\text { costs }\end{array}$ & $\begin{array}{l}\text { Resource } \\
\text { stream } \\
\text { Saved energy }\end{array}$ & $\begin{array}{l}\text { Emission } \\
\text { reduction } \\
\text { Waste reduction }\end{array}$ & $\begin{array}{l}\text { Productivity } \\
\text { Operation and } \\
\text { maintenance } \\
\text { Work } \\
\text { environment }\end{array}$ & $\begin{array}{l}\text { Activity type } \\
\text { Ease of } \\
\text { implementation } \\
\text { Corporate } \\
\text { involvement } \\
\text { Distance to core } \\
\text { process }\end{array}$ & Indirect effects \\
\hline
\end{tabular}

Based on these frameworks, it is evident that energy-efficiency improving investments constitute more than saving energy. Additional aspects are therefore necessary to address for a comprehensive understanding of these investments and the decision-making process for them.

The definition of energy efficiency as an output/input ratio (e.g. IEA 2012) implies that even if the main aim of the investment is not to improve energy efficiency, it can still be an energyefficiency investment if it improves the energy-efficiency ratio (Fleiter et al. 2012). A similar definition for the industrial sector is the ratio between useful output and energy input of a process (Patterson 1996). The difficulty lies in how to define useful output as well as energy input and what indicators to use. Patterson (1996) identifies four main types of indicators to measure the level of energy efficiency: thermodynamic, physical-thermodynamic, economicthermodynamic and economic. These different definitions are acknowledged; yet, for the scope of this thesis, it is sufficient to follow the simple definition of energy efficiency as an output/input ratio which can increase either by increasing output to a given level of input or to sustain a given level of output while reducing the input level of energy.

Whether an energy-efficiency investment is related to production or support processes may have further implications as well. Energy-efficiency investments related to support processes, e.g., ventilation or lighting, have lower initial costs and may be adopted on an operational level, whereas energy-efficiency investments related to production processes are capital-intensive and therefore more often subject to strategic decision making (Thollander and Ottosson 2010). That energy-efficiency investments often are related to something other than saving energy, such as an improvement of the production process, implies that most energy-efficiency investments may in fact be combinatorial investments. The presence of additional benefits also indicates that an energy-efficiency investment is more than an investment in energy efficiency. Another use of terms will therefore be applied in the following pages: for investments aimed solely at reducing energy efficiency, the term pure energy-efficiency investments will be applied. When this distinction is not made, the investments that are concerned are of a so-called combinatorial nature.

\subsection{Investment decision making}

As stated in the introduction, this thesis takes a process perspective on investment decision making. It takes its point of departure in the behavioural theory of the firm in which the path towards making a decision is process oriented and takes place through organisational decision

\footnotetext{
3 The categories do include other attributes but those considered as irrelevant for the scope of this thesis have been excluded from the table. For a full description, see Trianni et al. (2014).
} 
making4 (Cyert and March 1963). Their decision-making model is comprised by four concepts: (1) quasi-resolution of conflict, which builds on the notion that there are different goals represented within the organisation and there is a latent conflict between these goals; (2) uncertainty avoidance, which means that the organisations "achieve a reasonably manageable decision situation by avoiding planning where plans depend on predictions of uncertain future events and by emphasising planning where the plans can be made self-confirming through some control device" (p. 119); (3) problemistic search, simply meaning that search stems from an identified problem; and (4) organisational learning, meaning that organisations' behaviour is adaptive over time (Cyert and March 1963). The model is illustrated as a step-by-step process, yet in the form of a flow chart in which the start is arbitrary and the four concepts recur during the process.

The general decision-making model by Mintzberg et al. (1976) is comprised by three phases: identification, development and selection. These phases are described in terms of different routines. The first phase, identification, is described in terms of decision recognition and diagnosis. The second phase, development, is further described in terms of search and design. This is also the phase to which most resources are allocated. Finally, the phase of selection is described in terms of screening, evaluation-choice and authorisation. These phases do not need to occur sequentially but can be affected by so-called dynamic factors; for instance, the selection phase is itself described as a multistage and iterative process (Mintzberg et al. 1976). The view of the decision-making process not being simply sequential is consistent with the view of Cyert and March (1976) and the different stages of the decision-making process have been described in a similar manner in other studies as well (e.g. King 1975; Maritan 2001; Nutt 1993).

The models suggested by Mintzberg et al. (1976) and Cyert and March (1963) have been classified as decision-making models belonging to the rational or bounded rational stream of decision-making literature (Eisenhardt and Zbaracki 1992). A different classification of the decision-making literature has been provided elsewhere: Langley et al. (1995) review the literature on organisational decision making and depict two extremes: on the one hand, the rational and sequential process, as in the work by Herbert Simon, and on the other hand, the anarchical process where there is a lack of structure and sequence. The decision-making model according to Cyert and March (1963) is described as an anarchy model, yet with a remaining connection to rationality and sequential elements (Langley et al. 1995, p. 262). The model as described by Mintzberg et al. (1976) is on the other hand classified as an iterative sequence model, caught in between the two extremes (Langley et al. 1995). Langley et al. (1995) described the decision-making process as driven by the decision maker dealing with streams of issues rather than decisions. Previously, Cooremans (2012) has defined a model for investment decision making 5 which is based on the three phases and the dynamic factors according to Mintzberg et al. (1976) and further addresses the view of issue streams in accordance with Langley et al. (1995).

This thesis takes a process perspective on investment decision making and maintains the view of the decision-making process as a model "in between" with rational and sequential elements yet affected by other factors too (e.g. Cyert and March 1963; Mintzberg et al. 1976). In accordance with Langley et al. (1995), the decision makers involved in the decision-making process are acknowledged in this thesis. However, the thesis seeks to address how firms make decisions on capital investments improving energy efficiency and is therefore not committing to the view of issue streams.

\footnotetext{
4 Since the thesis is focused on the decision-making process for investments, specifically energy-efficiency investments as capital investments, the process is referred to as investment decision making or investment process; yet, this is still considered to be an organisational decision-making process.

${ }^{5}$ Although it is defined as a general model, it is applied in an energy-efficiency context.
} 


\subsubsection{A comprehensive take on the investment process}

Investment decision making is considered to go beyond the steps of the investment process and other factors will therefore be addressed for a comprehensive take on the investment process.

\subsubsection{Information}

One element of rationality is the degree of procedural rationality, defined as "the extent to which the decision process involves the collection of information relevant to the decision, and the reliance upon analysis of this information in making the choice" (Dean and Sharfman 1993b, p. 589). A lower level of procedural rationality for investments characterised by a higher level of uncertainty, often strategic decisions, has been stressed in the literature (Dean and Sharfman 1993b; Maritan 2001) as well as the opposite (Bourgeois and Eisenhardt 1988; Eisenhardt 1989a). In line with the latter, Van Cauwenbergh et al. (1996) found that formal investment analysis was an important instrument during the investment process for strategic investments and that formal analysis worked both as a communication instrument and a decision-making instrument. The communication aspect comes into play when other involved actors must be convinced of the investment project (Lumijärvi 1991; Van Cauwenbergh et al. 1996).

For investments improving energy efficiency there are different types of information, such as the attributes presented in previous frameworks (Fleiter et al. 2012; Trianni et al. 2014). For instance, Fleiter et al. (2012) address financial information such as expenditure, IRR and PB, information related to the technical context as well as the non-energy benefits (see section 2.3). Lumijärvi (1991) presents four types of arguments by which information can be framed in an investment proposal. These arguments can be economic, non-economic, strategic or related to technology. Despite their popularity, economic arguments such as PB are not always sufficient and strategic arguments are valued higher by senior management (Cooremans 2012), especially for larger investments (Lumijärvi 1991).

\subsubsection{Levels of decision making, authorisation and involved actors}

Investment decisions are made by managers on different levels at a firm, especially in large firms (Bower 1986). The extent to which management at different levels are involved in the investment process have been stressed to differ depending on the degree of uncertainty ${ }^{6}$ of the investment (Maritan 2001) as well as investment categorisation (Cooremans 2012). The leading actors in the decision process may also differ during the different steps of the investment process (Xue et al. 2008). Senior management, both on divisional and corporate level, have been suggested to be more involved concerning investments characterised by a high level of uncertainty, due to their strategic perspective (Maritan 2001). Cooremans (2012) concludes that if the investment is considered as non-strategic, senior management is not interested.

According to a previous study on corporate control of investments in Swedish multinational groups, senior managers are focused on strategic issues and coordinating investments (Segelod 1996). Profitability assessment of investments and investment proposals are performed on business unit level, which indicates a decentralised investment process. For these decentralised investment processes, the investment manual has been suggested to function as an important means of control, standardisation and creation of unitary principles (Segelod 1997). It has further been suggested that large corporations with a decentralised form of evaluation and with many investment proposals for investments related to production apply a manual for how capital budgeting should be practiced (Segelod 1997).

There may in turn be different investment committees for different investments, which serve to rank investment proposals (Segelod 1996). Senior management will then consider several investment proposals and prioritise between them (Butler et al. 1991). Prioritising between investments is one step towards deciding which investments that should finally be authorised

${ }^{6}$ Uncertainty here means uncertainty regarding the firm's production function, for instance technological uncertainty, and not regarding the external environment (Maritan 2001). 
and approved. The process of seeking approval on a higher hierarchical level is referred to as the authorisation routine (Mintzberg et al. 1976). When authorisation is required, information, or arguments, for an investment is prepared and presented to senior management (Mintzberg et al. 1976), such as investment committees (Segelod 1996). The stage at which approval takes place may also differ depending on the investment (Maritan 2001). For uncertain investments, senior managers are involved in initiating and preparing the proposals, which implies a faster approval: "as senior managers initiate and participate in the development of proposals for new ${ }^{7}$ investments, the stages of the investment process become blurred" (Maritan 2001, p. 523).

Decision making can also be discussed in terms of which levels that it occurs; the strategic, tactical or operative level (Bunse et al. 2009). Bunse et al. (2009) describe these levels as varying in descending hierarchical order. The strategic level is the top level in which decisions are more long-term and broad in character, evolving around for instance business areas. Investment benefits on this level are in turn intangible and non-financial in nature (Irani and Love 2002). The tactical level is focused on aspects such as the production process and capacity planning. At this level, decision making is thus a function to implement the goals established on strategic level. The third and final level, the operational, serves to transform the previously established goals into activities, such as amount of produced output (Bunse et al. 2009). Investment benefits on tactical and operational levels are therefore to a larger extent tangible (Irani and Love 2002).

Related to the different levels of decision making is that large firms are comprised by different departments and units, for instance different functional departments. A pulp and paper firm can for example have one department responsible for paper production and another for pulp production, and most firms have a separate financial department or a department for R\&D; the decision making process may then be influenced by department power (Provan 1989). The different needs and perspectives of different departments place a political dimension to decision making in organisations (Dean and Sharfman 1993a; Provan 1989) for instance in terms of bargaining between investments (Butler et al. 1991). This in turn adds conflict to decision making (Eisenhardt and Zbaracki 1992) as a result of various actors being involved in the process (Butler et al. 1991).

In addition to internal actors, such as senior managers and different departments, external actors should be addressed. When industries are characterised by a high level of technical complexity, for instance the pulp and paper industry, the suppliers play an important role in developing and providing technology (Del Río González 2005). The supplier then has a strong bargaining power (Porter 1980). On the other end of the value chain is the customer. Improved public image has been identified as an important driver for energy-efficiency investments (e.g. Del Río González 2005; Venmans 2014) as well as a non-energy benefit (e.g. Worrell et al. 2003). Hence, the role of the customer should also be taken into account.

\subsubsection{Capital budgeting practices}

When investment criteria are concerned, capital budgeting tools such as IRR and net present value (NPV) are often addressed, alongside the PB method. Despite its deficiencies, PB continues to be common in practice (e.g. Lefley 1996). PB has been found as the third most common evaluation method following NPV and IRR in the United States and Canada (Graham and Harvey 2001) and the most common tool among Swedish groups, especially within the basic, engineering and the chemical and pharmaceutical industries (Sandahl and Sjögren 2003). Capital budgeting tools such as the NPV and IRR are somewhat more common for strategic investments (Alkaraan and Northcott 2006). A use of a combination of capital budgeting tools has also been indicated (Cooremans 2012; Sandahl and Sjögren 2003), where PB may be used as a supporting measure (Lefley 1996).

\footnotetext{
7 "New" means investments aiming to build new capabilities and are investments characterised by a high level of uncertainty (Maritan 2001).
} 
PB is often criticised in academia since it does not take into account the timing of the returns or the returns occurring after the PB period (e.g. Armerin and Song 2014; Lefley 1996). It is used as a rule of thumb to examine investments and the use of short PB criteria assumes worst-case scenarios, favouring sure bets and applying short PB criteria then implies a higher required rate of return due to risk avoidance (Jackson 2010). It has in the literature been implied that firms consider energy-efficiency improving investments to be characterised by a higher risk than other investments. For instance, it has been indicated that firms apply stricter PB and other investment criteria for energy-efficiency improving investments than for investments in general (Cooremans 2012), which also has been found for small and medium-sized industrial firms (Qiu et al. 2015). In an Australian study on investments improving energy efficiency, 58 per cent of the included firms had a conservative or very conservative risk attitude towards energyefficiency improving investments and 80 per cent applied the PB method with an average criterion of 3.5 years (Harris et al. 2000). The same study also found that NPV only was used by 30 per cent of the firms to evaluate investments, using a discount rate of on average 13 per cent. Firms within the Swedish foundry and pulp and paper industry have shown similar findings; a majority of the studied firms applied PB criterion of 3 years or less (Thollander and Ottosson 2010) and comparable results have been indicated for the Swedish iron and steel industry (Brunke et al. 2014). On the other hand, Sandahl and Sjögren (2003) found that the average PB criterion was 2.8 years for capital budgeting decisions in general, which actually is a shorter PB period than what has been reported for investments improving energy efficiency.

In addition to finding shorter applied PB criteria for energy-efficiency investments, Qiu et al. (2015) also found that small and medium-sized industrial firms had implied discount rates of 40 to 45 per cent for energy-efficiency investments, as a reflection of high perceived uncertainty. Although the perceived risk of energy-efficiency improving investments appears as high, adjusting the discount rate according to the project risk is recommended by standard financial theory. However, there are findings on both energy-efficiency improving investments (DeCanio and Watkins 1998) and capital investments in general (Graham and Harvey 2001) that firms base their investment evaluation on firm risk and not investment risk.

\subsection{The additional benefits of energy-efficiency investments}

A systematic review of benefit concepts is provided in Paper I appended to the thesis. This section therefore aims to only briefly describe the additional benefits and illustrate how the thesis aims to contribute.

First, the literature lacks clear definitions of the available benefit concepts. These include for instance multiple benefits (e.g. IEA 2012), co-benefits (e.g. Ürge-Vorsatz et al. 2007) and nonenergy benefits (e.g. Pye and McKane 2000). This thesis therefore aims to provide a definition of the benefit concept to use in an industrial context (Paper I). Regardless of which concept that is used, these benefits can be described as additional benefits besides energy cost savings, stemming from energy-efficiency investments. For instance, Worrell et al. (2003) mentions reduced waste, improved productivity, reduced emissions, reduced maintenance, improved work environment or improved public image as examples of non-energy benefits. These benefits can be found amongst the driving forces identified for energy-efficiency investments, such as a green public image (e.g. Venmans 2014). Pye and McKane (2000) argue that it might be these additional benefits that will stimulate the investments, in particular the benefits related to productivity. Moreover, Eccels et al. (2014) mention a more engaged workforce and a more secure license to operate, both of which are examples of additional benefits, as possible factors that may contribute to the higher long-term performance indicated for so-called high sustainability firms ${ }^{8}$.

\footnotetext{
8 Other factors mentioned are a more loyal and satisfied customer base, better relationships with stakeholders, greater transparency, a more collaborative community and a better ability to innovate (Eccels et al. 2014, p. 19).
} 
Several studies have shown the potential of the additional benefits and indicated that these can exceed the energy cost savings (Hall and Roth 2003; Lilly and Pearson 1999; Lung et al. 2005; Pye and McKane 2000; Worrell et al. 2003). However, the robustness of these measures has been deemed uncertain since they stem from a limited number of observations, often through case studies (Worrell et al. 2003). Also, these studies are focused on an ex-post analysis, i.e. on reported benefits. Two previous frameworks for energy-efficiency investments include additional benefits as attributes that should be taken into account (Fleiter et al. 2012; Trianni et al. 2014). The extent to which additional benefits are acknowledged before the investment project is undertaken is however not considered in the literature even though their potential has been established repeatedly. It has been advocated that investment benefits of both a quantifiable and less quantifiable, i.e. intangible, nature should be taken into account in the investment process (Ashford et al. 1988). Since intangible benefits may be tangible in the long run (Grundy and Johnson 1993), acknowledging intangible benefits in the investment process can show long-term potentials of investments (Ashford et al. 1988). If additional benefits could be acknowledged already during the investment process, it could thus contribute to an increased adoption level of energy-efficiency investments.

\subsection{Energy-efficiency gap}

The energy-efficiency gap, i.e., the gap between the optimal and actual level of energy efficiency, is a proven paradox (e.g. Hirst and Brown 1990). Jaffe and Stavins (1994a) explained the presence of the gap by market failures, related to imperfect information and split incentives, and non-market failures, including high adoption costs and high discount rates, for instance caused by uncertainty about future energy prices and irreversible investments. Uncertainty and irreversibility as an explanation for the energy-efficiency gap has also been addressed elsewhere (Van Soest and Bulte 2001). Inertia in adoption behaviour and the fact that energy-efficiency technologies are cost effective on average but may not be for some firms are also mentioned as potential non-market failures (Jaffe and Stavins 1994a). It is suggested that if the market failures are eliminated, the so-called economist's potential and a narrow social optimum will be reached, and the so-called technologist's potential and a true social optimum will be achieved if the non-market failures also are removed (Jaffe and Stavins 1994a). The presence of both market and non-market failures as an explanation for the energy-efficiency gap is further established in a study of the gradual diffusion of cost effective energy-efficient technologies (Jaffe and Stavins 1994b). An additional explanation for the energy-efficiency gap is internal factors within the firms (DeCanio 1998, 1993) and firm characteristics (DeCanio and Watkins 1998). Even when cost effective energy-efficiency investments are concerned, it may not be enough for adoption since the firm's investment behaviour besides profit maximisation also is influenced by factors related to its organisation, structure and governance (DeCanio 1993).

Previously, the energy-efficiency gap has been extended to also include the potential from energy management practices (Backlund et al. 2012). On the contrary to investments in energyefficient technologies that often are capital intensive, energy management is not; instead, it is focused on aspects such as knowledge and awareness. The extended energy-efficiency potential is however suggested to be somewhat larger for non-energy intensive sectors in which the energy use is concentrated to support processes (Backlund et al. 2012).

\subsection{Previous research on investments improving energy efficiency}

A few studies have previously analysed firms' investment behaviour for energy-efficiency investments. In a Dutch survey, the overall results indicated that energy efficiency was an important factor in investment decisions ${ }^{9}$ (De Groot et al. 2001), which is also indicated in an Australian study (Harris et al. 2000). Even though potential energy cost savings are only one

\footnotetext{
${ }^{9}$ Approximately $8 \%$ considered it very important, 21\% important, $45 \%$ moderately important, $21 \%$ unimportant and $5 \%$ completely unimportant (De Groot et al. 2001, p. 723).
} 
investment criterion, it is the most important driver for investments improving energy efficiency (e.g. De Groot et al. 2001; Thollander and Ottosson 2008).

The probability of adopting energy-efficiency improving investments appears to increase with firm size, probably due to increased capital intensity (Arvanitis and Ley 2013). As for the reasons not to adopt energy-efficiency investments, a study based on firms with both energyintensive and non-energy intensive sectors concluded that small energy costs compared to other production costs, limited knowledge, not being related to core business, current equipment not yet worn out and budgetary constraints are factors that hampers the adoption of energyefficiency improving investments (Velthuijsen 1993). An organisational culture not favouring energy-efficiency issues and an uninterested top management have also been stressed as reasons for why energy-efficiency investments are not adopted (Cooremans 2012). For industries in which the production processes are characterised by a high level of complexity and interrelated processes, such as the pulp and paper industry (Del Río González 2005), there is also a high dependency on capacity utilisation (Posch et al. 2015).

Cooremans (2012) stressed the lack of a link to core business and low strategic character as reasons for why energy-efficiency investments are not prioritised. Four main conclusions are drawn: (1) profitability is an important, yet not decisive factor for investments; (2) the initial diagnostic phase and investment categorisation is crucial for the remaining process; (3) there is competition between investments; and (4) more strategic investments win the competition (Cooremans 2012, p. 505). The emphasis on core business and hence a more difficult situation for energy-efficiency investments are also confirmed in a study on Swedish industries (Sandberg and Söderström 2003). However, Venmans (2014) provide another explanation. Energy efficiency is considered as an activity related to core business for firms within energy-intensive industries ${ }^{10}$ and it is instead the optional character of this investment category that creates an obstacle: "the fact that energy-efficiency investments are in most cases optional (noncompulsory), creates a high hurdle rate for energy projects, driven by capital budgeting rules" (Venmans 2014, p. 140).

\subsubsection{Strategic character of capital investments}

Since previous studies on energy-efficiency improving capital investments have stressed lack of strategic character as a reason for why these investments are not adopted to a larger extent (e.g. Cooremans 2012; Sandberg and Söderström 2003), there is a need for a closer look on the meaning of 'strategic'. Strategic investments have been described as investments of high risk leading to intangible outcomes and affecting long-term performance (Alkaraan and Northcott 2006, p. 150) or simply having "a significant potential for improving corporate performance" (Van Cauwenbergh et al. 1996, p. 169). Cooremans $(2012,2011)$ defines strategic on the basis of Porter's (1985) concept of competitive advantage together with the resource based view, which yields the two dimensions value and cost. A third dimension, risk, is also added. An investment is defined as strategic "if it contributes to create, maintain, or develop a sustainable competitive advantage" (Cooremans 2011, p. 483) and competitive advantage is in turn defined as "a threedimensional concept, formed of three interrelated constituents: costs, value, and risks." (p. 486).

A link to core business is also discussed as a measure of strategic character and investments in production capacity, productivity and production processes are regarded as investment categories linked to core business (Cooremans 2012, 2011). Mintzberg et al. (1976) provide another definition: "strategic simply means important, in terms of the actions taken, the resources committed, or the precedents set." (p. 246) and this definition is also applied elsewhere; a decision is strategic if it "critically affect organisational health and survival" (Eisenhardt and Zbaracki 1992, p. 17). Reconnecting to the case of investments, this definition clearly includes strategic investments according to Cooremans's $(2012,2011)$ definition, but can

${ }^{10}$ Ceramic, cement and lime sectors in Belgium (Venmans 2014). 
also include investments that are not obviously related to a firm's core business, i.e. presumably also energy-efficiency investments.

\subsubsection{Barriers and driving forces to energy efficiency}

In light of the aforementioned energy-efficiency gap, a substantial part of the literature on improving energy efficiency has been devoted to understanding the barriers to energy efficiency (e.g. Brunke et al. 2014; Cagno et al. 2013; Cagno and Trianni 2014; DeCanio 1993; De Groot et al. 2001; Hasanbeigi et al. 2010; Howart and Andersson 1993; Rohdin et al. 2007; Rohdin and Thollander 2006; Sardianou 2008; Sorrell et al. 2000; Thollander and Ottosson 2008; Trianni et al. 2013; Trianni and Cagno 2012; Venmans 2014). Barriers can be defined as "... a postulated mechanism that inhibits investment in technologies that are both energy efficient and (apparently) economically efficient" (Sorrell et al. 2000, p. 11). Following the taxonomy of barriers by Sorrell et al. (2000), barriers to energy efficiency can be categorised as economic, behavioural and organisational, in which the economic perspective includes barriers such as heterogeneity, hidden costs, imperfect information or split incentives. Behavioural barriers are related to bounded rationality, form of information, credibility or inertia, whilst organisational barriers are related to for instance power (Sorrell et al. 2000).

Previously, a new taxonomy has been suggested in which barriers are categorised as external or internal (with respect to the firm) and according to the affected actor or area (Cagno et al. 2013). For instance, the barrier 'High initial costs' is a barrier categorised as external and affecting the designers and manufacturers, whereas the barrier 'Lack of time' is organisational and internal. This taxonomy distinguishes between barriers to investments, barriers to energy efficiency and intervention-related barriers to energy efficiency (Cagno et al. 2013). In addition to the taxonomies proposed by Sorrell et al. (2000) and Cagno et al. (2013), there are other suggestions on how to classify barriers to energy efficiency. For a more detailed review, see for example Cagno et al. (2013).

Empirically, barriers to energy efficiency have been addressed for the pulp and paper industry (Thollander and Ottosson 2008), the foundry industry (Rohdin et al. 2007; Trianni et al. 2013), the iron and steel industry (Brunke et al. 2014), cement industries (Hasanbeigi et al. 2010; Venmans 2014), Greek industries (Sardaniou 2008) and Dutch industries (De Groot et al. 2001). Barriers of an economic character, such as technical risks and the costs of potential production disruptions, are often ranked high (Brunke et al. 2014; Hasanbeigi et al. 2010; Thollander and Ottosson 2008). In the foundry industry, this barrier has been found more important for larger firms than on average (Trianni et al. 2014) as well as for group owned foundries (Rohdin et al. 2007). Other commonly high ranked barriers are related to access to capital, budget funding, priorities for capital investments, lack of time and other priorities (Brunke et al. 2014; De Groot et al. 2001; Hasanbeigi et al. 2010; Rohdin et al. 2007; Sardianou 2008; Thollander and Ottosson 2008; Trianni et al. 2013; Venmans 2014). DeCanio has studied the barriers within firms, also referred to as organisational and bureaucratic barriers (DeCanio 1998, 1993; DeCanio and Watkins 1998). Variables such as firm size together with a number of performance indicators show a positive relationship of joining a green lights programme (DeCanio and Watkins 1998) and larger firms also appear to be more willing to accept longer PB periods (DeCanio 1998). A summarising conclusion based on these studies is that organisational factors may affect the likelihood of joining an energy-efficiency programme (DeCanio and Watkins 1998) as well as the level and the variation in returns from energy-efficiency investments (DeCanio 1998).

The driving forces of energy efficiency are not as extensively studied as barriers (Brunke et al. 2014). However, there are a few examples. Three Swedish studies have identified a long term energy strategy, people with real ambition and commitment from top managers as high ranked drivers for energy efficiency (Brunke et al. 2014; Rohdin et al. 2007; Thollander and Ottosson 2008). Cost reductions from lower energy use is ranked as the most important driver (Brunke et al. 2014; Thollander and Ottosson 2008) and is identified as an important motive behind 
investments in energy efficiency (De Groot et al. 2001) and clean technologies (Del Río González 2005). In addition, improving environmental company image is a high ranked driver and motive behind energy-efficiency improvements (De Groot et al. 2001; Del Río González 2005; Thollander and Ottosson 2008; Venmans 2014).

However, the thesis does not study the barriers or driving forces of energy efficiency, neither does it intend to add to this line of theory; yet, both barriers and drivers are important to address since they constitute a foundation of previous research on investments improving energy efficiency. This line of theory can therefore be used as a frame of reference, especially for interpreting additional benefits and their role in the investment process for energy-efficiency improving investments.

\subsection{How the theoretical framework is applied in the thesis}

In this thesis, the point of departure (Paper I) was in the energy literature through a literature review of benefit concepts and investment behaviour for energy-efficiency investments. In Paper II, theory outside the energy field was added, yet limited to the steps of the investment process and capital budgeting practices since the main focus in this paper still was on additional benefits. In Paper III, the comprehensive view on the investment process was applied, including literature on general investment decision making as well as on energy-efficiency investments. The paper overview can therefore be extended with the papers' connection to the theoretical framework:

Table 3. Paper overview and connection to research aim and theoretical framework.

\begin{tabular}{lll}
\hline Paper & $\begin{array}{l}\text { Link to aim and research } \\
\text { questions }\end{array}$ & Theoretical framing \\
\hline
\end{tabular}

Paper I General aim, RQ1 and RQ3. Benefit concepts and

investment behaviour for

energy-efficiency investments.

Paper II General aim, RQ2 and RQ3. Additional benefits, energy-

(RQ1). $\quad$ efficiency investments, steps

of the process and capital

budgeting practices.

Paper III General aim, RQ1, RQ2 and A comprehensive take on the

RQ3. investment process and

investment decision making,

including additional benefits.

The thesis maintains the view that energy-efficiency investments often are combined investments and it is therefore necessary to include literature on investment decision making from outside the field of energy efficiency. Moreover, the thesis considers decision making as a process, which in turn is not restricted to a sequence of steps but affected by different factors as well, such as the actors involved, information addressed or how investments are authorised. In light of energy-efficiency investments being undertaken for other reasons than improving energy efficiency, acknowledging the additional benefits become increasingly important. The extent to which these are acknowledged and how they can be described in order to facilitate an inclusion in the investment process is the focus of this thesis. 


\section{Methodology}

In this chapter, the methodological approach and the research process are presented. The thesis is based on three studies: a literature review, an interview study and a case study. The chapter starts with a description of the research design and the research process of this thesis. It is then followed by a presentation of the first phase, the literature review. The explorative phase of the thesis then follows, discussing the applied qualitative approach and the main method for collecting data in this thesis, qualitative interviews. The two empirical studies are then presented separately. Finally, the evaluation of the trustworthiness of the thesis is discussed.

\subsection{Research design - a qualitative approach}

The aim of this thesis is to add new insights on investment decision making for capital investments by addressing the case of investments improving industrial energy efficiency and how additional benefits are and can be acknowledged in the investment process. Hence, the unit of analysis is the decision-making process. For understanding the processes through which actions, such as investment decisions, are reached, a qualitative approach has been stressed suitable (Maxwell 2009). The way in which the aim is formulated, i.e. as a statement of a phenomenon that is to be studied rather than to establish any causal relationship, speaks in favour of a qualitative approach since "...qualitative methods can be used to obtain the intricate details about phenomena such as feelings, thought processes, and emotions that are difficult to extract or learn about through more conventional methods" (Strauss and Corbin 1998, p. 11).

Qualitative research has five characteristics (Yin 2011, p. 19): first, it studies the meaning attributed to peoples' lives within real life conditions; second, it represents the perspectives of the participants of a study; third, it covers the context and conditions of the participants; fourth, it provides insights on actual or emerging concepts that can explain human social behaviour; and fifth, it seeks to apply multiple data sources. In other words, qualitative research enables an understanding of a research problem based on the perspective of the participants within their context. Applied to this thesis, having a qualitative approach makes it possible to study the investment decisions in the context that they are made and to capture perspectives that are easily lost through quantitative data collecting methods. Moreover, the concept of additional benefits in an energy-efficiency context is scarcely studied and not well-defined (which is further described in Paper I). As pointed out by Yin (2011), a qualitative method could therefore provide insights on this concept.

The research process can be divided into two phases and three studies, illustrated in Figure 1. It started with a literature review and was then followed by an exploration phase in which the main method was qualitative interviews (further described in 3.4). 


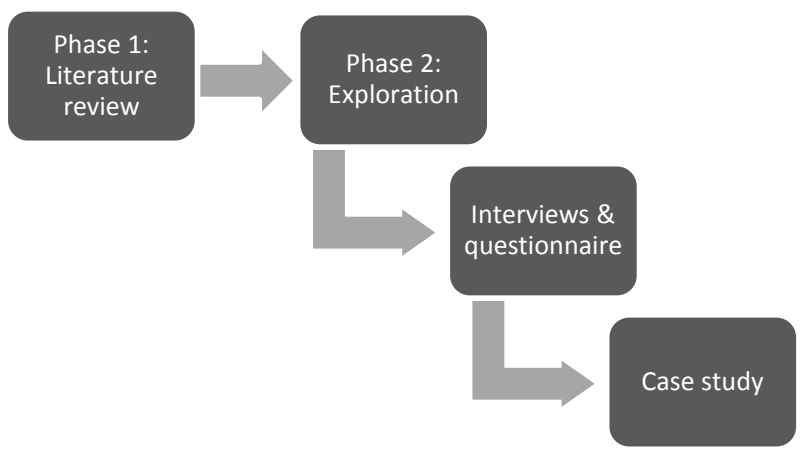

Figure 1. An illustration of the two phases in the research process.

The role of the literature review in the research process was to get acquainted with the research area, especially the literature on energy efficiency and energy-efficiency investments. The literature review covered both benefit concepts and investment behaviour of energy-efficiency investments. Its results could then be used to guide the research further. The literature review resulted in Paper I of this thesis. One of the paper's main conclusions was that the most adequate benefit concept to use in an industrial context was non-energy benefits. This benefit concept will therefore be used henceforth.

The second phase of the research process was exploration through empirical studies. This thesis is delimited to firms within the Swedish manufacturing industry. The included industries are high or moderately high energy users and all firms have 200 employees or more ${ }^{11}$. Firms from non-energy intensive sectors and SMEs are thus not considered in the thesis. Two empirical studies have been conducted of which the first included interviews with thirteen Swedish industrial firms and a smaller questionnaire, distributed and collected during a networking event. The aim of this study was to explore how Swedish industrial firms consider energyefficiency investments and the extent to which they acknowledged non-energy benefits. These interviews and the questionnaire sought to address research questions two and three of this thesis and also touched upon the first research question. In this study, analysis was made on a firm level. A limitation is the small sample size, yet the qualitative approach enables deeper insights. The results of this study are presented in Paper II.

During the interview study, it became evident that the respondents often had limited knowledge on the investment decision-making process beyond issues related to energy efficiency. In addition, there are few previous studies on energy-efficiency investments that have other respondents and hence other perspectives than that of energy managers; Cooremans (2012) is one rare example. Previous research has indicated that depending on the type of investment, the investment process may vary, for instance in terms of evaluation methods and involved actors. Therefore, a case study approach was chosen for the second empirical study since it would make it possible to engage relevant participants with different roles and at different organisational levels. It would then be possible to include respondents with knowledge on energy, strategic, financial and other aspects related to the investment decision-making process. Through this method, it was possible to refer to all three research questions addressed in this thesis. As in the first empirical study, level of analysis was the firm. The case study also included a case

11 All but one firm are considered as large with more than 250 employees (Eurostat 2014). 
investment, which enabled an analysis on the investment level as well. Although investment decision making is a process taking place within the firm (Cyert and March 1963, p. 19), analysis on investment level enables analysis of a specific case and opens up for the possibility that the decision-making process could be specific for a particular investment (Maritan 2001). The results of the third study are presented in Paper III.

However, the intention for the second empirical study was initially not to conduct a case study but a quantitative questionnaire study. The intention was to have a sequential mixed methods approach in which a qualitative study was to be followed by a quantitative study, expanding to enable generalised conclusions to be made (Creswell 2003). The aim of the questionnaire conducted in the first empirical study was therefore to function as a smaller pilot study. However, the results of the questionnaire were ambiguous and it could not be ensured that the respondents had understood the questions; alternatively, they did not have sufficient knowledge on the concept of non-energy benefits. This lead to the conclusion that at this stage, it would not be possible to ensure validity nor reliability in a quantitative questionnaire study and the choice was therefore made to continue with a qualitative approach. In hindsight, a qualitative approach is also more adequate in relation to the aim of the thesis.

\subsubsection{An interdisciplinary approach}

In order to fulfil the aim of this thesis, an interdisciplinary approach has been applied during the entire research process and the thesis draws upon the fields of business administration and energy systems. Interdisciplinary research can be defined as when research activities take place between researchers from different fields (Huutoniemi et al. 2010; Wickson et al. 2006). Aboelela et al. (2007) elaborate the definition further and state that interdisciplinary research should link or integrate theoretical frameworks from these different fields and the applied methodology should not be limited to any of the specific fields. In this thesis, these common research activities have taken place between the fields of business administration and energy systems. Combining different fields can also be seen as means to enhance creativity (Alvesson and Sköldberg 2000).

The research has been conducted in close collaboration with another doctoral student, Therese Nehler. This has involved general discussions on the project but mainly concerned the data collection and the writing of Paper II. We have also had different roles in the two empirical studies. In the first study, which involved 13 interviews with energy managers and a questionnaire, Therese Nehler had a leading role in both preparing and collecting the data. In the second study, the case study, it was the opposite. I initiated the contact as well as had a leading role in preparing and collecting the data. In the next pages, each phase of the research process is described in detail, including a statement of my contribution. Using the typology by Huutoniemi et al. (2010), the interdisciplinary research of this thesis can be described as broad in scope, since the involved fields belong to the social sciences and the technological sciences and both empirical and theoretical in interaction. Even though the main interaction has involved collecting different types of data to solve an interdisciplinary research problem, theoretical interdisciplinarity is evident through the use of theory. Finally, it is epistemological in its goal orientation since the aim of this thesis has been to add new knowledge insights on a research problem (Huutoniemi et al. 2010).

Besides us two doctoral students, three senior researchers from both fieleds also belong to the research project. I consider having access to a research group a strength since it has enabled opportunities for valuable feedback during the research process.

\subsubsection{The role of theory}

In this thesis, there has been a continuous interplay between theory and the empirical data. More specifically, the thesis started with a deductive approach (Bryman and Bell 2011) through a literature review. The suggestions proposed from the literature review (see Paper I) was used 
to guide the research further. During the two empirical studies that followed, it was a continuous process of comparing the data with theory, both during data collection as well as during analysis. For instance, Paper II has been in a peer review process. This means that we have had to return to both data and theory several times. For the case study, this process has brought both new theoretical influences as well as spurred further empirical observations. Dubois and Gadde (2002) describe this process as abduction and systematic combining. This means that theory is continuously contrasted with the empirical phenomena, and vice versa (Dubois and Gadde 2002). Eisenhardt (1989b) argues for a similar process in which theory and the empirical data are iteratively compared. Even though both Eisenhardt (1989b) and Dubois and Gadde (2002) restrict their discussion on the role of theory for case studies, the same reasoning has been discussed for qualitative research in general (Strauss and Corbin 1998).

Dubois and Gadde (2002, p. 559) further argue that "an abductive approach is fruitful if the researcher's objective is to discover new things" and that "the original framework is successively modified, partly as a result of unanticipated empirical findings, but also of theoretical insights gained during the process". In line with the aim of this thesis, to add new insights on the investment process and on the concept of non-energy benefits, having an abductive approach to theory is therefore appropriate. Moreover, when data from different fields are combined, as in interdisciplinary research, an inductive approach can have the risk of only leading to 'common sense', whereas an abductive approach can enable more interesting results (Alvesson and Sköldberg 2000).

\subsubsection{Externally funded research project and academic freedom}

The research constituting this thesis has been conducted within a research project funded by the Swedish Energy Agency. This implies an issue of being "stuck in-between" the funded research project and the thesis, or balancing between market orientation and academic orientation as discussed by Ylijoki (2003). The overall aim of the research project ${ }^{12}$ has of course had an impact on the thesis and its research subject. However, I have sought to protect my academic freedom as a researcher. For instance, the choice to take a comprehensive view on the investment process was not stated in the research project but emerged during the research process.

Eisenberg (1988) identifies two possible threats to academic values and academic freedom when the research is externally funded: distortions of the viewpoints and claims of academic researchers, and distortion of the research agenda ${ }^{13}$. The threat of distortion of viewpoints and claims involves the risk of adapting viewpoints and scientific claims in order to please the funder's agenda. The second threat, distortion of the research agenda, involves the risk of the research conducted being led by the goals of the sponsor (Eisenberg 1988). These threats may lead to the researcher being constrained by the aims of the sponsor, falsified or exaggerated results to please the sponsor, or on the contrary lead to not publishing results that are not in favour of the sponsor. As already noted, the research presented in this thesis has been affected by the research project within which it has been conducted. Still, choices regarding research focus as well as methods, for instance to do a case study, have been made without being implied by the goals of the research project. Moreover, the form of funding has not affected what results that have been published.

\subsubsection{Anonymity}

In this thesis, the interviewees as well as the participating firms have been granted anonymity. Especially for the case study, this was important since internal information has been used. Not anonymising the participants can also lead to censoring of the presentation of the research to

\footnotetext{
12 The aim of the research project was to analyse how energy can become a strategic issue for Swedish industry, by analysing the costing, capital budgeting and decision models used to guide companies' strategies, also including nonenergy benefits.

${ }^{13}$ Eisenberg (1988) also states the possible threat of secrecy of results, but this has not been an issue in this research project since no such claims have been stated.
} 
protect the participants (Guenther 2009), which in this study could be both the interviewees and the participating firms. However, anonymity implies a lack of transparency and replicability but it should not have affected the results in any way.

\subsection{Paper overview and link to applied methods}

The methods used during these two phases and their resulting three studies can be added to the paper overview as below.

Table 4. Paper overview and link to research aim, theoretical framing and methods used.

\begin{tabular}{llll}
\hline Paper & $\begin{array}{l}\text { Link to aim and } \\
\text { research questions }\end{array}$ & Theoretical framing & Method \\
\hline
\end{tabular}

\begin{tabular}{|c|c|c|c|}
\hline Paper I & General aim, RQ1 and RQ3. & $\begin{array}{l}\text { Non-energy benefits and } \\
\text { investment behaviour for } \\
\text { energy-efficiency } \\
\text { investments. }\end{array}$ & Literature $r$ \\
\hline Paper II & $\begin{array}{l}\text { General aim, RQ2 and RQ3. } \\
\text { (RQ1). }\end{array}$ & $\begin{array}{l}\text { Non-energy benefits, energy- } \\
\text { efficiency investments, steps } \\
\text { of the process and capital } \\
\text { budgeting practices. }\end{array}$ & $\begin{array}{l}\text { Interviews } \\
\text { questionna }\end{array}$ \\
\hline Paper III & $\begin{array}{l}\text { General aim, RQ1, RQ2 and } \\
\text { RQ3. }\end{array}$ & $\begin{array}{l}\text { A comprehensive take on the } \\
\text { investment process and } \\
\text { investment decision making, } \\
\text { including non-energy } \\
\text { benefits. }\end{array}$ & Case study \\
\hline
\end{tabular}

A more thorough description of the three studies is provided below.

\subsection{Phase 1: Literature review}

The first phase in the research process for this thesis was to do a literature study. The aim of conducting the literature review was in accordance with the aim stated by Tranfield et al. (2003, p. 208): " The aim of conducting a literature review is often to enable the researcher both to map and to assess the existing intellectual territory, and to specify a research question to develop the existing body of knowledge further".

In line with the aim of the thesis, the study aimed to review literature both on benefit concepts and aspects related to investments in energy efficiency, which in this study was referred to as investment behaviour.

\subsubsection{Benefit concepts}

The part of the literature study which focused on benefit concepts followed the methodology for a systematic review with predefined keywords and search strings with inclusion and exclusion criteria (Needleman 2002; Tranfield et al. 2003). A systematic review ensures a replicable and transparent process, which in turn constitutes a quality criterion for literature reviews (Tranfield et al. 2003). Furthermore, systematic reviews can reduce potential bias of the reviewer (Collins and Fauser 2005; Needleman 2002).

The background to the review of the benefit concepts was a report by the International Energy Agency (IEA), in which the term multiple benefits is used as a collective concept for describing 
the benefits of energy efficiency (IEA 2012). The benefits range from industrial productivity to health benefits or climate change mitigation. The IEA (2012) includes the three concepts ancillary benefits, co-benefits and non-energy benefits in multiple benefits. There was however no definition of which concept that should be used in which context, for instance in an industrial context. The three benefit concepts were therefore reviewed individually to discover possible differences and similarities between the concepts. This could then serve as a basis to establish which benefit concept that should be used in an industrial context, such as the research of this thesis.

The literature search was performed during autumn/winter 2013 and the characteristics of the search process is summarised in Table 5 below.

Table 5. Description of systematic literature search.

\begin{tabular}{ll}
\hline Benefit concepts: & Ancillary benefits, co-benefits, non-energy benefits \\
Search period: & Autumn/winter 2013, re-checked spring 2015 \\
Database: & Scopus \\
Subject area restriction: & Energy \\
Type of papers: & Articles and conference papers \\
Search settings: & Search in title, abstract, and keywords \\
\hline
\end{tabular}

As described in Table 5, the literature search covered the three concepts ancillary benefits, cobenefits, and non-energy benefits. It was set to only include articles and conference papers within the subject area energy, since the aim of the study was to review the benefit concepts related to energy efficiency. Conference papers were included since this type of papers is common within the field and excluding them from the search could then lead to incomplete results.

The search criteria resulted in the following search string:

TITLE-ABS-KEY ( “CONCEPT” ) AND (LIMIT-TO ( SUBJAREA , “ENER” ) ) AND ( LIMIT-TO ( DOCTYPE , "ar" ) OR LIMIT-TO ( DOCTYPE, "cp" ) )

The search and selection processes for each benefit concept is visualised in the flow diagram in Figure 2 below. 


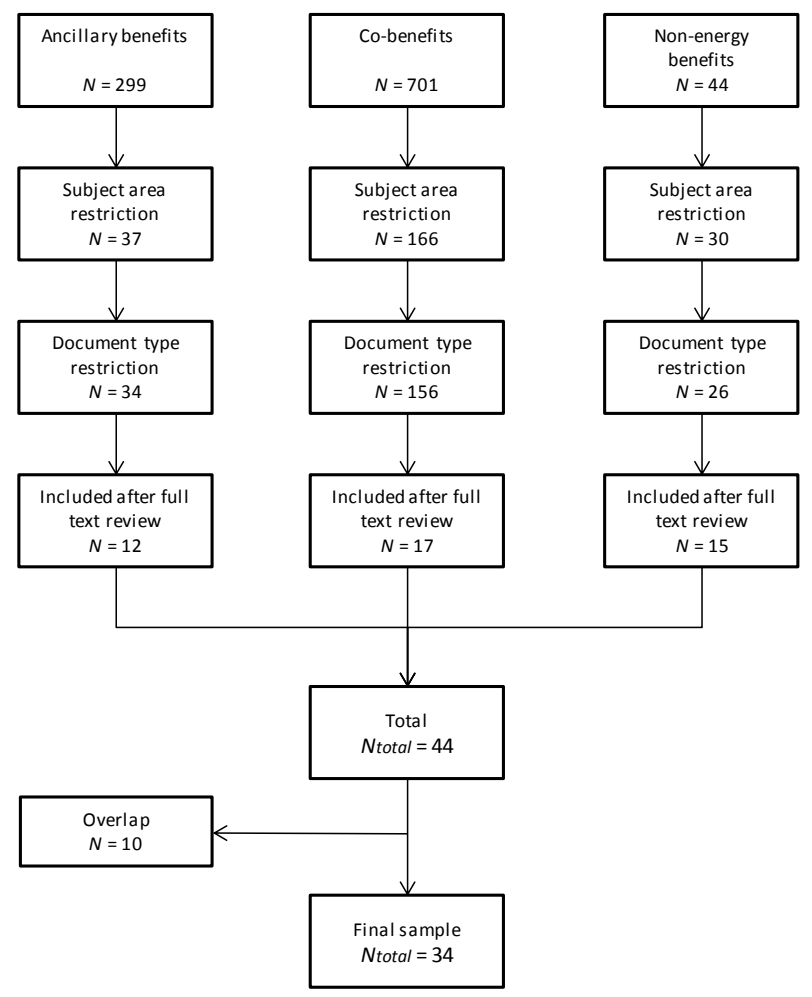

Figure 2. Flow diagram of the search and selection processes for the three benefit concepts.

As Figure 2 shows, the number of hits varied between the concepts and co-benefits appears to be the most common benefit concept in the energy field in general. In total, there was an overlap of ten articles and conference papers, as visualised in Figure 2, of which three concerned nonenergy benefits and at least one of the other two concepts, and eight concerned ancillary benefits and co-benefits. One of the overlapping articles used all three benefit concepts. This is described further in Paper I.

When other document types than articles and conference papers had been excluded, the abstracts of the remaining papers were reviewed. The papers were kept for full text revision if the benefit concepts were considered as additional benefits, to ensure that the included papers had a perspective consistent with the aim of the study. Papers not available online, which especially concerned older conference papers, were excluded before the final step. After full text revision, 34 articles and conference papers were included.

\subsubsection{Investment behaviour}

The second part of the literature study, here referred to as investment behaviour, had initially also a systematic approach in the search process. Pre-defined search terms, such as "decisionmaking" or "investment evaluation" were applied in a search string corresponding to the one used for the benefit concepts. However, it became evident that it would be a much more extensive search and selection process since these terms are used broadly in various research fields. It was either a problem of finding relevant studies, or the search resulted in a number of hits that was impossible to manage. For instance, even after restricting the search to the subject 
area Energy, the number of hits for "decision-making" is approximately 9000 . The traditional method for literature reviews was therefore chosen.

Through this traditional snow-balling method, relevant studies, both journal articles and conference papers, were identified through reference lists and citations of papers known to the author, which can be described as going backwards (Webster and Watson 2002). This process implies that this part of the study will lack in transparency and replicability, which is considered a limitation. However, there are also advantages of the traditional approach, of which one is that the traditional approach enables a more comprehensive coverage than the systematic approach, which is narrower in its nature (Collins and Fauser 2005). Dijkers (2009) also argues that the traditional approach occasionally may be more suitable than the systematic approach, especially when the research question is broader. When findings from one stance of research is to be translated into another, a systematic approach may not be preferred since the focus of the review probably is not narrow enough (Dijkers 2009; Hammersley 2002).

Comparing the first and second part of the literature study, the second part on investment behaviour may to a certain extent actually benefit from a traditional approach, even though it was not the intention from the beginning and despite its limitations. The aim of this part of the review was to integrate the findings with the results on the benefit concepts. It serves to be more comprehensive and has a broader focus than the part on benefit concepts. The part on benefit concepts is narrower in scope and therefore favours from a systematic approach, while the part on investment behaviour is broader and has an integrative aim, and may therefore favour from a traditional approach.

\subsubsection{Analysis and implications for the subsequent research process}

During the analysis phase of the literature review, literature from the field of IT investments was included. The reason is that this field had experienced similar difficulties in identifying and measuring additional benefits (e.g. Dempsey et al. 1998; Irani and Love 2002). The findings from this field were combined with those on the benefit concepts within the energy field and a matrix for categorising non-energy benefits was developed. The integration of the results from the review of the benefit concepts and those on investment behaviour for energy-efficiency investments resulted in four suggestions, including which benefit concept to use (non-energy benefits) and how these benefits could be included in the investment process of investments improving energy efficiency. Together with the developed matrix, these suggestions were then addressed in the subsequent empirical studies.

\subsubsection{My contribution}

The results from the literature review are presented in Paper I, of which I am the single author. A previous version of the paper was presented at the eceee Industrial Summer Study in Arnhem, June 2014 and published in the conference proceedings (Rasmussen 2014). With consent from the eceee, the paper was revised and submitted to a journal in 2015. The journal is also informed of the preceding conference paper.

\subsection{Phase 2: Exploration through a qualitative approach}

In this thesis, the empirical data is mainly based on qualitative methods: an interview study and a case study, both of which can be considered as exploratory. A small questionnaire, based on three questions, was used together with the interview study. However, as described further in Paper II, the questionnaire revealed ambiguous answers and its results are therefore scarcely used in this thesis. The reason for still including them is that they provided methodological conclusions, both for the concept of non-energy benefits and for the overarching research process of the thesis, as described in section 3.1. Yet, since the main results are based upon qualitative interviews, the research approach in this thesis is considered to be qualitative. For the same reason is the first empirical study further on addressed to as the interview study. 


\subsubsection{Qualitative interviews}

Semi-structured, qualitative interviews have been the main method for collecting data, both in the interview study and in the case study. Interviews are the most common method for collecting data in qualitative research, (Yin 2011) and they constitute a platform for producing contextual knowledge (Kvale and Brinkmann 2012).

Interview guides were used during the interviews. Interview guides, or interview protocols, are applied and strictly followed during structured interviews, but they are also recommended to be used as guidance during qualitative interviews (Yin 2011). The interview guides were in both studies semi-structured, which means that they were comprised of suggested questions to be asked during the interviews, but the order of the questions could vary and additional questions, such as follow-up questions, could be asked (Kvale and Brinkmann 2012). By having a semistructured approach, the interviewees are also allowed to describe the world from their perspectives (Yin 2011). This approach also forces the researcher to continuous reflection and analysis during the interview, which is a criterion for ensuring quality of qualitative interviews (Alvesson 2003; Kvale and Brinkmann 2012; Yin 2011). A reflexive approach is advocated by Alvesson (2003), who states that reflexivity "stands for conscious and consistent efforts to view the subject matter from different angles and avoid or strongly a priori privilege a single, favoured angle and vocabulary" (p. 25). In both the interview study and the case study the majority of the questions were open-ended, although a few could be answered with simple yes/no answers. This was however rarely the case; the interviewees in most cases provided extensive answers and if not, follow-up questions were posed. Before the interviews took place, the interview guides were reviewed within the research group.

Face-to-face interviews grant the interviewer access to non-linguistic information such as expressions and so forth (Kvale and Brinkmann 2012) and four of the interviews in the interview study and eight of the interviews in the case study were therefore performed on site. To a large extent, the interviews were conducted by more than one researcher since multiple investigators, or investigator triangulation, can provide additional support for the findings as well as additional perspectives on the data (Eisenhardt 1989b; Stake 1995). The transcripts and the results have also been reviewed and validated within the research group.

Below, the methods applied in each empirical study are described in detail.

\subsection{Interview study}

In this study, thirteen interviews were conducted. The interviewed firms belonged to the Swedish industrial sector and were selected on the basis of energy use and participation in the PFE. The reason for selecting firms participating in the PFE was that it can be assumed that these firms previously have worked with energy-efficiency issues. Other firms were selected on the basis of energy use. The characteristics of the firms are described in Table 6. The annual energy use is displayed as an interval to ensure anonymity of the firms. 
Table 6. Firm characteristics of the interviewed firms.

\begin{tabular}{lllll}
\hline Firm & Industry & $\begin{array}{l}\text { Annual energy use } \\
\text { (GWh) }\end{array}$ & $\begin{array}{l}\text { Participating } \\
\text { in PFE }\end{array}$ & Implemented EMS \\
\hline A & Pulp and Paper & $1000-5000$ & Yes & Yes \\
B & Engineering & $40-100$ & No & No \\
C & Pulp and Paper & $100-1000$ & Yes & Yes \\
D & Engineering & $40-100$ & No & Yes \\
E & Engineering & $40-100$ & No & No \\
F & Engineering & $40-100$ & Yes & Yes \\
G & Basic metal & $1000-5000$ & Yes & Yes \\
H & Engineering & $100-1000$ & No & No \\
I & Chemical & $1000-5000$ & Yes & Yes \\
J & Chemical & $100-1000$ & Yes & Yes \\
K & Other & $100-1000$ & No & N/A \\
L & Basic metal & $100-1000$ & Yes & Yes \\
M & Pulp and Paper & $1000-5000$ & Yes & Yes \\
\hline
\end{tabular}

All firms are large energy users and belong to company groups. All firms except Firm B are considered as large with more than 250 employees. Firm B is however a large medium sized firm with approximately 200 employees. As presented in Table 6, eight of the firms have participated in the PFE and nine of the firms have implemented energy management systems ${ }^{14}$ (EMS). Firm B did not have a separate EMS but had integrated energy management in its environmental management system.

The interviewees were energy managers or had a similar role description. They were responsible for energy issues at the firm and occasionally also interacted with management or belonged to energy steering committees. They were chosen as interviewees since they would have insights on how the firm worked with energy issues and energy-efficiency investments. One limitation was however that the interviewees often had limited insights on the investment process in general. For instance, it could be that the interviewees knew which PB criterion that was required or what other evaluation tools that were used, but not why certain criteria were applied. The lack of deeper insights in to strategic priorities were also a limitation, especially since the importance of strategic priority for investments has been emphasised previously (e.g. Cooremans 2012). Nevertheless, for the case of energy-efficiency investments it is clearly necessary that the respondents have knowledge on energy issues, which makes energy managers highly relevant as respondents.

An overview of the interviews is presented in Table 7 below. Eight of the telephone interviews took place during winter 2013/2014, and the ninth phone interview and the four on-site interviews took place during summer 2014. The interviews were conducted together with or by a research colleague, Therese Nehler.

${ }^{14}$ An energy management system implies a systematic coordinating, controlling, realising and improving of energy (SEA 2014b). The international standard for energy management systems is ISO 50001 (SEA 2014c). 
Table 7. Overview of interviews.

\begin{tabular}{llll}
\hline Interviewed firm & Duration & On site/by phone & Interviewer \\
\hline Firm A & 1 hour & By phone & TN \\
Firm B & 1 hour & By phone & TN \\
Firm C & $1: 10$ hours & By phone & TN \\
Firm D & $1: 20$ hours & By phone & TN \\
Firm E & 1 hour & By phone & TN \\
Firm F & 50 minutes & By phone & TN \\
Firm G & 1 hour & By phone & TN \\
Firm H & 40 minutes & By phone & TN \\
Firm I & 2 hours & On site & TN, JR \\
Firm J & $1: 20$ hours & On site & TN, JR \\
Firm K & $1: 05$ hours & On site & TN, JR \\
Firm L & $1: 45$ hours & On site & TN, JR \\
Firm M & 1 hour & By phone & TN \\
\hline
\end{tabular}

JR: Josefine Rasmussen, TN: Therese Nehler, research colleague.

The interviews evolved around three main topics: (1) Background information such as energy use of the firm and the role of the interviewee; (2) Investments, which included motives, implemented energy-efficiency investments and measures, the investment process and evaluation methods such as capital budgeting tools; and (3) Non-energy benefits, which included aspects such as the firm's experience of these benefits, observed non-energy benefits and the quantification of non-energy benefits. These topics were developed based on previous literature ${ }^{15}$. Four questions were added to the final five interviews. One of them, which concerned costs and risk, was however excluded from the analysis since the interviewees were unable to answer it.

\subsubsection{Data analysis}

On the contrary to quantitative methods, there are fewer and less standardised methods for analysing qualitative data. Yin (2011) describes the analysis process in five phases, which describes the analysis process of this study: compilation of data; dissemble; re-assemble; interpreting; and concluding. Compilation of data involves compiling and ordering the data, in this study it included recordings, transcripts and notes. Dissemble of data implies that the data is broken down into smaller pieces and occasionally coded. In this study, structural coding was applied, which is a method appropriate when there are multiple participants and semistructured interview guides are used (Saldaña 2009). One additional reason for why structural coding was chosen is that it enables both quantitative and qualitative follow-up (Saldaña 2009). Quantitative analysis of the interviews was applied in graphic form and in the form of frequency tables. For the researcher, it enables a more efficient analysis of a large data set (Namey et al. 2008). In structural coding, the data is summarised and categorised, i.e. coded, on the basis of content and related research questions, and it has also been described as a question-based method (Namey et al. 2008).

When the data has been dissembled, it should be re-assembled (Yin 2011). This implies that the data should be re-organised and re-combined in different ways, in this study by using tables and graphs. Yin (2011) stresses that moving between the second and third step is an iterative loop that can be repeated, as well as for the two final steps: interpretation and conclusions. The interpretation and drawn conclusions can have implications on the preceding steps and create a new loop. This was also the case in this study, especially for the step between interpretation and re-assembling of the data. In this way, the focus was not only on the structuring and coding of

15 The first eight interviews and the interview guide is also briefly described Nehler et al. (2014), a conference paper preceding Paper II. 
the data, but also on multiple interpretations, which is stressed to enable results that are rich in scope and quality (Alvesson 2003).

\subsubsection{Questionnaire}

The questionnaire served as a smaller pilot study since the initial aim was that a larger questionnaire study would follow, as described in section 3.1. The purpose of the questionnaire was especially to see to which extent it would be possible to address non-energy benefits through a questionnaire, which to the author's best knowledge had not been attempted before. Thus, it was of an explorative nature and served to provide descriptive results.

It was distributed in 2014 during a networking event for firms participating in the PFE. The event was arranged by the Swedish Energy Agency and the questionnaire was distributed by one of their representatives. The questionnaire responses were collected during the same day. 43 firms from energy intensive firms participated during this networking event and the questionnaire was distributed to representatives from these firms. The respondents worked with energy-related issues, including issues related to the PFE.

The questionnaire consisted of three questions, presented in Table 8, of which the first was an open-ended question and the remaining two on non-energy benefits were presented in tables. In the second question, the respondent should mark "yes" or "no" for whether or not they had experienced the non-energy benefits listed in the table. If they marked "yes", they should also rank the importance of that non-energy benefit when performing energy-efficiency investments on a scale of 1 to 5 . The third question was based on the same list of non-energy benefits as the second questions. The respondents should mark "yes", "no, but it is included as a comment in the application", or "no, it is not included". If they marked the last option, they were asked to provide the underlying reason. A definition of the concept non-energy benefits was presented on the first page.

Table 8. Questionnaire questions and response rates.

\begin{tabular}{ll}
\hline Question & Response rate \\
\hline $\begin{array}{l}\text { 1. What capital budgeting tools do you normally } \\
\text { apply at your firm before making an investment } \\
\text { decision? For example PB, NPV, or IRR. }\end{array}$ & $72 \%$ (31 firms) \\
$\begin{array}{l}\text { 2. Have you experienced the listed non-energy } \\
\text { benefits when making energy-efficiency } \\
\text { investments at your firm? }\end{array}$ & $70 \%$ (30 firms) \\
$\begin{array}{l}\text { 3. State whether or not the listed non-energy } \\
\text { benefits are included in the investment } \\
\text { calculation when making energy-efficiency } \\
\text { investments at your firm. }\end{array}$ & $63 \%$ (27 firms) \\
\hline
\end{tabular}

The three questions are stated in Table 8 above, along with the response rate for each question. 63 per cent of the firms responded all three questions. Four of the firms participating at the networking event were also included in the interview study. However, only three of them responded to at least one question. The questionnaire did not require the name of the respondent, only the firm. It is thus not known whether or not it is the same person who has answered the questionnaire that has been interviewed.

For analysing the questionnaire results, the same approach as for the interviews was applied, using structural coding followed by re-assembling of the data. However, it was soon discovered that the results of the questionnaire were ambiguous; several firms stated in the third question that they monetised non-energy benefits which they in the second question had claimed not to 
have experienced. This is in Paper II and the thesis interpreted as an indication that the respondents have not fully understood the questions, alternatively the respondents have not understood the concept of non-energy benefits enough to be able to properly answer question two and three. The results from the questionnaire are therefore scarcely used in this thesis, as already stated, but still included since they provide methodological conclusions.

\subsubsection{My contribution}

The interview study is in this thesis presented in Paper II, which I co-authored with my research colleague Therese Nehler who is the main author. Therese Nehler conducted the majority of the interviews alone; I participated in four of them. During these four interviews, Therese Nehler was the main interviewer and I only posed follow-up questions. The interview guide and the questionnaire were both constructed by Therese Nehler but I provided feedback on them before the data collection started. After the interviews were completed, I transcribed two of the interviews and Therese Nehler the remaining eleven.

Both of us read and analysed the transcripts and the questionnaire results. When writing the paper, I was main responsible for the two chapters on previous research, while Therese Nehler was main responsible for the method chapter. For the remainder of the paper, we contributed equally in writing. How to frame the paper and how to analyse and present the results were continuously discussed between us during the writing of the paper. We have also shared the work during the revision process.

\subsection{Case study}

For the second empirical study, a case study approach was chosen. The aim of the study was to add new insights on investment decisions for energy-efficiency investments and how these are made, including how energy-efficiency investments are motivated, the investment process and how non-energy benefits are acknowledged. By conducting a case study, it would be possible to include participants with different roles and from different organisational levels, which could enable a more in-depth analysis of the investment decision-making process compared to the interview study (Yin 2009). A case study can provide the researcher with a higher level of detail and thus enable a more multifaceted description of the research phenomenon (Flyvbjerg 2006).

Multiple case studies are often advocated because of higher reliability and robustness (Baxter and Jack 2008; Yin 2009). Single case studies are however sometimes preferred, for instance when the researcher is faced with a representative case and "the objective is to capture the circumstances and conditions of an everyday or commonplace situation. [...] The lessons learned from these cases are assumed to be informative of the average person or institution" (Yin 2009, p. 48). Making decisions on capital investments is part of everyday-business at an industrial firm. In this study, energy-efficiency investments are defined as a type of capital investments. How firms make decisions on energy-efficiency investments is scarcely studied, in particular with a process perspective. The potential of non-energy benefits have also been stressed recently (e.g. Pye and McKane 2000; Worrell et al. 2003), but less is known on how they are acknowledged by firms today. This case study can therefore add new insights on energyefficiency investments and non-energy benefits, as the rationale suggested by Yin (2009).

This aim implies that it is not the particular case that is of interest, i.e., it is an instrumental case study rather than an intrinsic (Stake 1995). As discussed in section 3.1, the case study was conducted both on firm and investment level, indicating similarities to an embedded single case study (Yin 2009). The case study includes a case investment, which became of interest at the initial stage of the study. The case investment was a large, strategic energy-efficiency investment, and was therefore interesting for this study. In that sense, the inclusion of the case investment can be considered as a step towards an intrinsic case study (Stake 1995) and a case study of a unique case (Yin 2009). However, the unit of analysis is always the investment decision-making process and the case investment is used to generalise conclusions from 
investment level to firm level as well. This approach, in line with the design of an embedded single case study, may enable deeper insights from the study (Yin 2009). It may often be difficult to categorise a case study as either intrinsic or instrumental (Stake 1995) and this case study clearly has strains of both, even though it is mainly instrumental and the main level of analysis is the firm.

\subsubsection{Case selection}

In line with the overall aim of the thesis, the aim of the case study was to study energy-efficiency investments and non-energy benefits. A suitable case firm was therefore selected on the basis on three premises. First, to establish that the case firm had an interest in energy-efficiency issues, it should preferably belong to an energy-intensive industry. Second, it should be large enough to enable an analysis on different organisational levels. Third, beyond having an interest in energyefficiency issues, the firm should have made, and preferably be doing, energy-efficiency investments to enable an analysis of the investment process as well as the extent to which and how non-energy benefits were acknowledged.

\subsubsection{The case firm}

The case firm, Pulp \& Paper (henceforth P\&P), is a large firm belonging to the Swedish pulp and paper industry. It produces paper, board and pulp products. The firm, among other firms in this industry, has a strong sustainability profile. P\&P participated in the PFE programme and is a large energy user; the pulp and paper industry accounts for half of the total energy use in Swedish industry (SEA 2013). Thus, P\&P fulfils the first selection criterion of having an interest in energy issues. $\mathrm{P} \& \mathrm{P}$ is also considered as a large firm, with a number of production facilities in Sweden as well as abroad, which fulfils the second requirement. Finally, since the firm has a strong sustainability profile and has participated in the PFE programme, they have performed energy-efficiency investments and measures and are systematically working with energy issues. Firms who participated in the PFE were required to undertake energy-efficiency investments with a PB period less than three years, which implies that the firm at least has undertaken smaller energy-efficiency investments. By studying press releases, it was established that also larger energy-efficiency investments had been or were planned to be undertaken, such as the case investments, before initiating the case study. Since the three selection criteria are fulfilled, it enables a study of the investment process for capital investments improving energy efficiency, including the extent to which non-energy benefits are acknowledged.

In line with the aim of the thesis, the case serves to provide insights which can contribute to an analysis of how investment decisions are made for capital investments and how non-energy benefits are acknowledged. The case firm is thus a representative case (Yin 2009) for an energyintensive firm regularly making decisions on energy-efficiency investments.

\subsubsection{The case investment}

A case investment was studied more closely. The case investment was a major investment categorised as strategic due to its importance for the future production at the mill. It consisted of a new evaporation plant and an upgraded recovery boiler, which both are part of the production process. Besides being strategically important for future production, it was a major energyefficiency investment, which is why it has been analysed further in this case study. It primarily aimed to and has resulted in improved energy efficiency, lower emissions, increased production and reduced maintenance costs. It had its background in requirements of environmental compliance necessary to keep the production permit.

When this case study was initiated, the case investment had been installed and implemented since approximately one year. This has enabled an analysis of the investment process before as well as its results, yet only in retrospective which should be considered as a limitation. 


\subsubsection{Data collection}

Using different sources of data is advocated for in case studies since it may improve the validity (Yin 2009) and the credibility (Lincoln and Guba 1985). The data collection in the case study is mainly based on semi-structured interviews on group level and at one of P\&P's mills, but the case study also includes internal and external documents. An informational introduction meeting and a tour at the mill also serve as a basis for data collection.

\subsubsection{Interviews}

Ten interviews at P\&P have been made. Two of the interviews were made by phone and the others on site. Eight of the interviews were made together with a research colleague.

Table 9. Overview of interviews in the case study.

\begin{tabular}{llll}
\hline Interviewee & Duration & On site/by phone & Interviewer \\
\hline Group Sustainability Director & 40 minutes & On site & JR \\
Department Manager Sulphate Pulp Mill & 40 minutes & On site & JR, TN \\
Investment Manager & $1: 15$ hours & By phone & JR \\
Environmental Manager & 1 hour & By phone & JR, TN \\
Division Manager & $1: 15$ hours & On site & JR, TN \\
Investment Manager Strategic Projects & $1: 45$ hours & On site & JR, TN \\
Financial Manager & 1 hour & On site & JR \\
Maintenance Manager & 45 minutes & On site & JR, TN \\
Technical Controller & 45 minutes & On site & JR, TN \\
Manager Work Environment \& Safety & $1: 15$ hours & On site & JR, TN \\
\hline
\end{tabular}

JR: Josefine Rasmussen, TN: Therese Nehler, research colleague.

The interviewees have different responsibility areas and do to a various extent and in different ways work with energy-efficiency investments and/or energy-related issues. The interviewees also have different roles in the investment process; some of them work with identifying needs and preparing investment projects and applications, whereas others are involved with controlling and evaluating investment applications. A detailed description of their roles and responsibilities can be found in Paper III (Appendix A).

The interviewees relevant for the study were partly identified beforehand and partly along the way. When the case study started, the group sustainability director and the division manager were the first to be contacted and interviewed. Before data collection started, participants with responsibilities such as those of the environmental manager and financial manager were also of interest to include due to their connection to energy-efficiency issues and investment decision making. The remaining interviewees were identified as the study proceeded.

The interviews were semi-structured and based on an interview guide, which was based on the literature as well as previous research within the research project, for comparative reasons. It evolved around three main themes: motives and support for energy-efficiency, the investment process and non-energy benefits. The questions in the interview guide were adjusted depending on the role of the interviewee but always originated from the same structure. The first theme stems from previous research indicating that the motives behind capital investments improving energy efficiency may vary from cost savings to improved environmental image (Del Río González 2005; Thollander and Ottosson 2008). In the meantime, energy efficiency has also appeared to be of low priority (Cooremans 2012; De Groot et al. 2001).

The reasoning behind the second theme is that the decision whether to adopt an investment is reached through a process and that this process may differ depending on the characteristics of the investment (e.g. Cooremans 2012; Maritan 2001), and there is thus a possibility that this might be the case for energy-efficiency investments too. The third theme, non-energy benefits 
relates to the previously identified potential of non-energy benefits (e.g. Pye and McKane 2000) and the lack of research on how firms actually consider non-energy benefits when making investments in energy efficiency.

The aspects covered by the questions in the interview guides are stated below in Table 10, ordered by the theme to which it belongs.

Table 10. The aspects covered in the interview guide by theme.

\begin{tabular}{ll}
\hline Theme: & Included aspects: \\
\hline 1. Motives and support & $\begin{array}{l}\text { Motives managerial support, } \\
\text { priority, strategic importance. }\end{array}$ \\
2. Investment process & $\begin{array}{l}\text { Steps of the process, involved } \\
\text { actors, information, evaluation } \\
\text { methods and criteria. }\end{array}$ \\
3. Non-energy benefits & $\begin{array}{l}\text { If, how and when non-energy } \\
\text { benefits are included, importance } \\
\text { of different benefits. }\end{array}$ \\
\hline
\end{tabular}

All interviews were recorded and transcribed. The main results and conclusions from each interview were summarised. The interviewees were then given the possibility to read and provide feedback on this, by email or phone, to ensure credibility (Lincoln and Guba 1985) and validity (Cho and Trent 2006; Yin 2009). Seven of the interviewees responded and confirmed or provided feedback on the results, such as clarifications and alternative explanations.

\subsubsection{Other data sources}

In addition to the interviews, data was collected through internal and external documents. External documents were retrieved through P\&P's official website and included financial reports, sustainability reports, press releases and similar information. Internal documents were retrieved during the interviews or through e-mail correspondence and included templates for investment applications and applications for risk analysis, other appendices and internal presentations. The risk analysis applications were not distributed due to confidentiality, only displayed on screen during the interviews. However, their parameters were described and recorded and notes were taken during this part of the interviews.

An informational meeting and an on-site tour are other data sources. The informational meeting was mainly focused on the case investment, which is described below, but also included an introduction on the mill and its operations.

\subsubsection{Case investment}

Data collection on the case investment started with an informational meeting with the division manager, who at the time for the interviews was responsible for the recovery boiler and the evaporation plant, and a tour on site. Four researchers from the research project were present during this meeting. This meeting was not recorded but detailed notes were taken. The case investment was then addressed during all interviews except one (Coordinator Investment Planning), since the interviewee had not been involved to a sufficient extent. The questions on the case investment included aspects from all three themes. Three of the interviewees, the environmental manager, the division manager and the investment manager for strategic projects, are considered as key informants on the case investment.

In addition, internal and external documentation on the case investment were used, such as press release, internal presentations and reports. 
The analysis of the investment decision-making process for the case investment was made in retrospective since the investment was already implemented. It would of course have been beneficial to follow the investment during the investment process since an analysis in retrospective is limited to the view of the participants. However, the case investment was addressed in all but one interview and other data sources were used. In this way, several perspectives could be accounted for when the investment decision-making process for the case investment was analysed, increasing the level of transparency.

\subsubsection{Data analysis}

As previously described, the main method for collecting data in the case study has been through qualitative interviews and all interviews have been recorded and transcribed. Attribute codes were then assigned to the participants, since the case study included multiple participants with different roles (Saldaña 2009). By analysing the attributes of the participants on an early stage, it was possible to identify potential participants that should be contacted. The attributes included participant (interviewee), title, role description, place of work (mill or on group level), and interview details (date, on site or phone, duration, interviewer(s)).

Within-case analysis and cross-case analysis are common analysis methods for case studies (Ayres et al. 2003; Eisenhardt 1989b; Yin 2009). Since this is a single case study, only the former has been applied in this thesis. Eisenhardt (1989b, p. 540) describes the aim of within-case analysis "to become intimately familiar with each case as a stand-alone entity", and suggests detailed case descriptions. In this case study, verbatim transcripts of the interviews have been made based on the recordings. Documents such as the investment application and risk analysis have also been described in detail. The importance of the individual accounts, i.e. for each participant, as well as the accounts for all participants has been stressed for within-case and qualitative analysis (Ayres et al. 2003). The interviews were therefore analysed both individually and on an aggregated level. Each transcript were summarised individually to identify important aspects of the experience of each interviewee and to identify significant statements (Ayres et al. 2003). To enable an analysis of the firm, the transcripts and summaries were aggregated for further analysis. Since this case study is considered to be instrumental rather than intrinsic, categorical aggregation is preferred (Stake 1995).

The method for categorising the data was similar to the method used in the interview study, structural coding. Since the case study also involved multiple participants and primarily was based on semi-structured interviews, structural coding would be considered suitable (Saldaña 2009). However, since the case study involved other forms of data as well, such as a case investment and documents, the data was summarised and categorised based on content and theme, rather than based on question, which is the case for structural coding (Namey et al. 2008; Saldaña 2009). The main themes for which data was categorised by were motives and support, the investment process and non-energy benefits. In addition, a number of subthemes were also identified for the main themes 'Motives' and 'Investment process': Motives includes managerial support for energy-efficiency investments, motives and aim of energy-efficiency investments and priority against other investments; Investment process includes steps, investment classification, evaluation methods and information. The material from other data sources have been analysed on the basis of the same themes as the interviews. Examples of how the data was analysed according to the themes are provided in Table 11 below. 
Table 11. Examples of how data was analysed according to the themes

\begin{tabular}{ll}
\hline Theme & Example from transcripts \\
\hline 1. Motives and support & $\begin{array}{l}\text { "Energy efficiency is strategically important"; "Energy efficiency is } \\
\text { 'just money'...; "The economic part is the main motive because it } \\
\text { concerns so much money". }\end{array}$ \\
2. Investment process & $\begin{array}{l}\text { "It depends on the size of the investment"; "We have to start with a } \\
\text { pilot study"; "The pre-project is more detailed"; "For the smaller ones } \\
\text { it is payback time". }\end{array}$ \\
3. Non-energy benefits & $\begin{array}{l}\text { "The communicative value is substantial"; "Then you'll have these } \\
\text { effects on lighting and noise... Yes, positive side effects arise"; } \\
\text { "Increased productivity will be added to the calculation". }\end{array}$ \\
\hline
\end{tabular}

\subsubsection{My contribution}

The results from the case study are presented in Paper III in this thesis, of which I am the single author. Eight of the interviews were conducted with my research colleague Therese Nehler and I did the other two alone. During the interviews which were conducted together with Therese Nehler, I was the main interviewer and Therese Nehler had a supporting role and posed followup questions. I transcribed all except for one of the interviews. The interview guides were constructed by me but feedback was provided by Therese Nehler as well as by other members of our research group before the data collection started. One exception was the interview guide for the interview with the work environment engineer, which was mainly prepared by Therese Nehler.

\subsection{Evaluation of trustworthiness criteria}

Ensuring validity is a prerequisite for establishing quality of a research study. A research study has a high level of validity if the data has been collected and interpreted to adequately reflect the reality of the research problem that has been studied (Yin 2011). There are a number of criteria for evaluating research and conventional terms are for instance internal and external validity, reliability, replicability and objectivity (e.g. Bryman and Bell 2011; Yin 2009). However, since these criteria to a large extent are grounded in the positivistic paradigms and often more suitable for evaluating research with a more quantitative approach, Lincoln and Guba (1986, 1985; Guba 1981) developed four criteria corresponding to the conventional criteria: credibility (internal validity); transferability (external validity and generalisability); dependability (reliability and replicability) and confirmability (objectivity). These criteria are adequate to evaluate research which is context dependent and are referred to as criteria of trustworthiness (Lincoln and Guba 1986, 1985). Since the main research approach in this thesis is qualitative and context dependent, the criteria for evaluation suggested by Lincoln and Guba (1985) are therefore considered as more adequate than the conventional criteria and will be applied in this thesis.

Cho and Trent (2006) propose a holistic approach to validity in which aspects from both transactional and transformational validity are combined depending on the purpose of the research. Transactional validity includes techniques such as member-checking and triangulation, with the aim to ensure credibility and trustworthiness. It is defined as "an interactive process between the researcher, the researched, and the collected data" (Cho and Trent 2006, p. 321). Transformational validity is defined as "a progressive, emancipatory process leading toward social change that is to be achieved by the research endeavour itself"; rather than applying different techniques, transformational validity is described as a process in which the researcher is self-reflective and strives for a deeper understanding of the research problem (Cho and Trent 2006, pp. 321-322). The criteria for evaluation suggested by Lincoln and Guba (1985) which are applied in this thesis are mainly of a transactional character but with transformational elements. 
The evaluation is thus based on a holistic approach to validity as proposed by Cho and Trent (2006).

The credibility criterion concerns the truth value of the research (Guba 1981; Lincoln and Guba 1985). The main method to establish credibility in the thesis has been through triangulation, which can be carried through by triangulating methods, data sources or investigators (Lincoln and Guba 1986). Triangulation of methods and sources has been applied during the entire research process. Triangulation of methods and data sources can verify or strengthen a result (Yin 2011), assist in the search for convergence (Creswell and Miller 2000), reduce the risk of bias due to a single method (Maxwell 2009) and is a method to ensure transactional validity (Cho and Trent 2006). Especially in case studies, the possibility to use multiple methods and sources is considered a strength (Yin 2009). For the thesis as a whole, a literature review, interview study and the case study method have been applied. The questionnaire included in the interview study could also be mentioned as an additional method and source of data. The case study was in turn based on interviews, a meeting and internal and external documents. Multiple investigators have been involved when collecting the data as well as when interpreting the data. The use of multiple investigators, or triangulation of investigators, has the advantage that it can add different perspectives to the interpretation of the data as well as increase the confidence of the findings (Eisenhardt 1989b).

A second technique for establishing credibility is through member checking (Lincoln and Guba 1985), which also is described as respondent validation (Maxwell 2009) and an additional measure of transactional validity (Cho and Trent 2006). In this thesis, technical member checking in which the respondents assess the accuracy of the collected data, was applied for the case study. Unfortunately, this was not the case for the interview study. However, Maxwell (2009) argues that the responses of the interviewees are equally valid as the feedback received from member checking. The recordings and transcripts of the interviews are therefore considered as a measure for credibility for the interview study, although member checking would have strengthened its credibility further.

Establishing credibility can be a method for ensuring dependability, and vice versa (Lincoln and Guba 1985). The establishing of credibility through triangulation and member checking is thus a means to establish the third criterion, dependability, which concerns the consistency of the results (Lincoln and Guba 1985) and relates to the reliability of the results and how stable they are (Guba 1981; Whittemore et al. 2001).

The second criterion suggested by Lincoln and Guba (1985), transferability, concerns the applicability of the findings, or the conventional term generalisability. The term transferability implies that the findings, rather than being possible to generalise, are transferable to another context (Guba 1981). The difficulties in generalising from qualitative studies, and especially from case studies, are often mentioned as a drawback of qualitative studies. Flyvbjerg (2006) however argues that generalisation as a key to scientific progress is overestimated and that context-dependent knowledge may be at least as important; "the force of example is underestimated" (p. 228). For qualitative research, analytical generalisation is also discussed in which the drawn conclusions are applied to similar contexts where the studied phenomenon is of interest (Yin 2011). Baxter and Chua (1998) argue that it is possible to theorise beyond the empirical case, since the empirical case serves to exemplify the research problem; it is a matter of "moving from the general to the local to the general" (p. 80). In this thesis, the general research problem was studied in the local context of the included firms. The findings presented in this thesis should thus be transferable from the studied firms to a more general context, both for energy-efficiency investments specifically and capital investments in general. Considering the characteristics of the included firms, the findings would be transferable to other large firms within the manufacturing industry and possibly also additional industries with similar characteristics, such as high energy intensity and rather complex production processes. 
Transferability is suggested to be established by the use of thick descriptive data (Lincoln and Guba 1985; Creswell and Miller 2000). These thick descriptions aim to provide a "data base that makes transferability judgements possible on the part of potential appliers" (Lincoln and Guba 1985, p. 316, emphasis in original). The data should thus be rich and described in detail to enable an assessment of others than the researcher (Lincoln and Guba 1985; Maxwell 2009). Maxwell (2009, p.244) further stresses that "In interview studies, such data generally requires verbatim transcripts of the interviews, not just notes on what you felt was significant". All interviews in this thesis were recorded and verbally transcribed. Moreover are the roles of each interviewee described, as well as the characteristics for the firms in the interview study and the case firm, as well as the case investment in the case study. The aim has been to describe the methods with as high level of detail as possible for all three studies that constitute this thesis.

The fourth criterion, confirmability, concerns neutrality and corresponds to the conventional term objectivity (Lincoln and Guba 1985; Guba 1981). Triangulation is again stated as a technique to apply in order to achieve confirmability (Guba 1981), which has been applied in this thesis. Practicing reflexivity is also suggested by Guba (1981). Reflexivity implies an approach in which both the researcher and the researched are context dependent and influence each other (Alvesson and Sköldberg 2000). The aim with reflexivity is "to inspire a dynamic, flexible way of working with empirical material and escapes a simple theory/method divide." (Alvesson 2003, p. 26). When working with interviews, which is the main method in this thesis, Alvesson (2003) further argues that it may be insufficient to only rely on the number of interviews, since it may still only be a reflection of one perspective. The number of interviews in this thesis might not be considered as particularly large (thirteen plus ten), but they represent perspectives of different functions, organisational levels and firms. As described in section 3.4, continuous reflection was strived for during the semi-structured interviews. These aspects of reflection and reflexivity can be considered as elements of transformational validity (Cho and Trent 2006). 


\section{Summary of papers}

As described previously, the thesis is comprised by three papers which are summarised in this chapter.

\subsection{Paper I: Towards a broader view on energy-efficiency investments: An integrative review on benefit concepts and investment behaviour}

Energy cost savings alone are not always enough to motivate an investment. Acknowledging the additional benefits can therefore increase the probability of adopting these investments. However, various benefit concepts are applied and there is a lack of definitions of these concepts and how they are composed. The aim of this paper is therefore to review the literature on benefit concepts and define the benefit concept most adequate to use in an industrial context and propose a categorisation that can facilitate an inclusion of the additional benefits. Moreover, the paper also aims to review the literature on investment behaviour for energy-efficiency investments and to integrate the results with the findings on additional benefits. The overall aim of this combined review is thus to assess on what basis investment decisions are made for energy-efficiency investments, and if and how additional benefits can be acknowledged for energy-efficiency investments.

The combined review was performed by applying both the systematic and the so-called traditional review method. The three benefit concepts ancillary benefits, co-benefits and nonenergy benefits were reviewed systematically, whereas the literature on investment behaviour for energy-efficiency investments was reviewed using the traditional method.

The results identified non-energy benefits as the benefit concept most adequate to use in an industrial context. Non-energy benefits are defined as the additional benefits related to an industrial energy-efficiency investment, beyond energy cost savings. These benefits can be defined according to level of quantifiability and when in time they are expected to occur. A matrix is presented in which non-energy benefits can be categorised according to these two characteristics: level of quantifiability and time frame. By integrating these results with the findings on investment behaviour for energy-efficiency investments it is suggested that the inclusion of quantifiable non-energy benefits in the investment evaluation may increase the priority level for energy-efficiency investments. Non-energy benefits characterised by a low quantifiability level, especially benefits considered strategic, can be included at a later step during the investment process to select between similar investment projects. Moreover, it is suggested that acknowledging non-energy benefits in the investment process can contribute to overcome known barriers to energy-efficiency investments, such as uncertainty, and reinforce driving forces, for instance green public image. A summarising conclusion is thus that by defining and categorising non-energy benefits by level of quantifiability and time frame, they can be included in the investment process for energy-efficiency investments, enabling a more accurate assessment of these investments' potential. 


\subsection{Paper II: How do firms consider non-energy benefits? Empirical findings on energy-efficiency investments in Swedish industry}

In addition to energy cost savings, industrial energy-efficiency investments may result in nonenergy benefits. However, there is a lack of knowledge regarding firms' experiences of nonenergy benefits and the extent to which these benefits are considered by industrial firms when they are about to undertake energy-efficiency investments. Therefore, this paper aims to explore firms' perspectives on non-energy benefits of industrial energy-efficiency investments and the extent to which non-energy benefits are considered in the investment process. The paper also aims to explore investment motives and critical aspects for adopting energy-efficiency investments.

Data was collected through thirteen interviews conducted at firms within Swedish manufacturing industry and a questionnaire, distributed and collected at a networking day for firms participating at the PFE programme. The interviews covered questions on non-energy benefits, investment motives and aspects related to the investment process, such as capital budgeting tools. The questionnaire included three questions, covering applied capital budgeting tools, what non-energy benefits the firm had observed and which non-energy benefits that were monetised and included in the investment analysis. However, the questionnaire indicated ambiguous answers on non-energy benefits. The results of the questionnaire are therefore interpreted with caution.

The results indicate that the primary motive behind energy-efficiency investments is potential cost savings, although there in general were several motives behind an investment. Energy efficiency was considered an important issue at the firms, yet profitability and PB time appeared as the critical factors for adopting energy-efficiency investments. Due to the importance of a short PB time, it was difficult for energy-efficiency investments to be accepted on the basis of energy cost savings alone. Regarding non-energy benefits, the results indicated that various nonenergy benefits had been observed by the included firms, especially non-energy benefits related to reduced maintenance costs and improved work environment. However, few were monetised and included in the investment evaluation due to a lack of knowledge on how to measure the benefits. Thus, the results indicate a potential for benefits that could be monetised, for example non-energy benefits related to reduced waste, reduced emissions or production.

On the basis of the identified motive behind energy-efficiency investments and the importance of profitability and PB for adoption, it is suggested to denote non-energy benefits as costs or revenues and to take both level of quantifiability and time frame into account. By addressing these characteristics, non-energy benefits can be acknowledged in a way that contributes to a framing of energy-efficiency investments that meets the profitability requirements. 


\subsection{Paper III: How to acknowledge non-energy benefits? A case study approach on the investment process for energy-efficiency investments}

The decision to adopt an investment is reached through a process, which involves different actors, information and different evaluation methods. This also includes energy-efficiency investments. Yet, studies on energy-efficiency investments are in general restricted to include participants with an energy perspective, such as energy managers. Moreover, previous studies are often restricted to only one step of the investment process - evaluation methods. This paper therefore aims to take a comprehensive perspective on the investment process for energyefficiency investments by taking a novel approach through a case study in which participants at different organisational levels and with different responsibilities are engaged. The aim of the paper is to analyse how investment decisions are made and how and when non-energy benefits are acknowledged in the investment process.

As mentioned above, a case study method was applied. The case study was conducted at a firm within the Swedish pulp and paper industry. Interviews were made on group level and at one of the firm's mills. The interviewees had different roles in the investment process, ranging from identifying needs to prioritising between investment projects. In addition to interviews, used data also includes internal and external documents, such as an investment manual, sustainability reports and presentations. The investment process for a case investment was also analysed closely. The case investment was a major and complex capital investment resulting in improved energy efficiency as well as non-energy benefits.

The results indicate that energy-efficiency investments follow the same investment process as other categories of capital investments. The investment process is a multistage process in which the investment manual plays a vital role, both in terms of what information that should be included in the investment applications and how the investment applications should be authorised. The investment process is consistent for different investment categories, but varies depending on investment size and a higher degree of procedural rationality is indicated for larger investments. Suppliers are highly involved in the investment process at an early stage. Energy-efficiency investments are primarily motivated by their potential cost savings, yet a costsavings paradox is indicated for energy-efficiency investments: they are both driven and hampered by their cost-savings motive. When non-energy benefits are acknowledged in the investment process, it takes place at an early stage with emphasis on a limited number of main effects. For example, this can include non-energy benefits related to reduced maintenance and reduced emissions. Moreover, non-energy benefits such as improved public image, environmental benefits, availability in production, quality and work environment are considered to be of high importance. In light of the cost-savings paradox and the emphasis on a limited number of main benefits, it suggested that non-energy benefits related to these prioritised issues should be highlighted when possible in order to show that energy-efficiency investments lead to more than energy cost savings, which in turn can increase the priority for these investments. 


\subsection{Linking main findings to paper overview}

The paper overview can now be extended with the papers' main findings:

Table 12. Paper overview and link to research aim, theoretical framing, methods applied and main findings.

\begin{tabular}{|c|c|c|c|c|}
\hline Paper & $\begin{array}{l}\text { Link to aim and } \\
\text { research questions }\end{array}$ & $\begin{array}{l}\text { Theoretical } \\
\text { framing }\end{array}$ & Method & Main findings \\
\hline Paper I & $\begin{array}{l}\text { General aim, RQ1 and } \\
\text { RQ3. }\end{array}$ & $\begin{array}{l}\text { Non-energy } \\
\text { benefits and } \\
\text { investment } \\
\text { behaviour for } \\
\text { energy-efficiency } \\
\text { investments. }\end{array}$ & $\begin{array}{l}\text { Literature } \\
\text { review }\end{array}$ & $\begin{array}{l}\text { Non-energy benefits are defined } \\
\text { as the most adequate concept for } \\
\text { an industrial context. A matrix } \\
\text { for classifying non-energy } \\
\text { benefits according to } \\
\text { quantifiability and time frame is } \\
\text { presented, along with four } \\
\text { suggestions on how to integrate } \\
\text { non-energy benefits with } \\
\text { investment decision making. }\end{array}$ \\
\hline Paper II & $\begin{array}{l}\text { General aim, RQ2 and } \\
\text { RQ3. (RQ1). }\end{array}$ & $\begin{array}{l}\text { Non-energy } \\
\text { benefits, energy- } \\
\text { efficiency } \\
\text { investments, steps } \\
\text { of the process and } \\
\text { capital budgeting } \\
\text { practices. }\end{array}$ & $\begin{array}{l}\text { Interviews and } \\
\text { questionnaire }\end{array}$ & $\begin{array}{l}\text { Presents findings on how firms } \\
\text { perceive non-energy benefits } \\
\text { and the extent to which these } \\
\text { are considered in the investment } \\
\text { process. Empirically applies the } \\
\text { matrix from Paper I and adds the } \\
\text { dimensions of costs and } \\
\text { revenues to non-energy benefits. }\end{array}$ \\
\hline Paper III & $\begin{array}{l}\text { General aim, RQ1, RQ2 } \\
\text { and RQ3. }\end{array}$ & $\begin{array}{l}\text { A comprehensive } \\
\text { take on the } \\
\text { investment process } \\
\text { and investment } \\
\text { decision making, } \\
\text { including non- } \\
\text { energy benefits. }\end{array}$ & Case study & $\begin{array}{l}\text { Studies the investment process } \\
\text { by engaging participants at } \\
\text { different organisational levels, } \\
\text { both at the mill and on group } \\
\text { level. The investment process } \\
\text { can be described as a multistage } \\
\text { process, varying by investment } \\
\text { size and not specific for energy- } \\
\text { efficiency investments. If non- } \\
\text { energy benefits are } \\
\text { acknowledged, it takes place at } \\
\text { an early stage and focus is on the } \\
\text { main effects. }\end{array}$ \\
\hline
\end{tabular}




\section{Discussion}

The aim of this thesis has been to add insights on firms' investment decision making for capital investments and additional benefits by addressing the case of capital investments improving energy efficiency. The aim and research questions, stated below, have been addressed through three papers. This chapter seeks to further elaborate on the results presented in the papers to provide a synthesised discussion on the research findings.

Research questions:

1. What characterises the investment process for energy-efficiency investments?

2. To what extent do firms acknowledge additional benefits when making investment decisions on investments improving energy efficiency?

3. How should additional benefits be:

a. Defined in an industrial context?

b. Acknowledged in the investment process?

\subsection{The investment process}

As stated in the quote by Pye and McKane in the introduction, "In order to make a more compelling case for energy efficiency and pollution prevention, it is critical to understand the decision-making process of business management." (2000, p. 182). The first research question of this thesis therefore sought to address the characteristics of the investment process for capital investments improving energy efficiency.

Previous research has indicated energy-efficiency investment to be subject to a conservative risk attitude (Harris et al. 2000) and stricter PB criteria, leading to high implied discount rates (Qui et al. 2015). Investment categorisation has also been indicated to influence the subsequent investment process, and not in favour of energy-efficiency investments (Cooremans 2012). However, according to the findings of this thesis the investment process for energy-efficiency investments does not seem to differ from that of other investments. Besides contributing to the literature on energy-efficiency investments, this finding enables the results to be transferable to a general context.

From the two empirical studies conducted within this thesis, the investment process for energyefficiency investments appears to be consistent with the suggested general model, including the phases of identification, development and selection (Mintzberg et al. 1976) and the concepts constituting the behavioural decision-making model (Cyert and March 1963). These phases or steps do not happen strictly sequentially (e.g. Cyert and March 1963; Mintzberg et al. 1976). A fourth phase, implementation, is added in line with Cooremans (2012) to illustrate the path after an investment project has been accepted. 
The findings on the investment process will be discussed below in relation to the phases identification, development and selection. The findings are then synthesised in section 5.1.3 and Figure 3.

\subsubsection{Identification}

The investment process is initiated in the identification phase (Mintzberg et al. 1976) as a result of a problemistic search (Cyert and March 1963), i.e. based on an identified need. According to the results of Paper II and Paper III, an investment in improved energy efficiency is most commonly initiated close to production, often related to maintenance. In some cases they may also be initiated from the environmental department (Paper III) or as a result of an energy audit (Paper II).

In this thesis, the first phase of the investment process has been addressed through investment motive and categorisation, i.e. what is the identified need stimulating the investment process, since previous research has indicated these aspects as critical for the subsequent investment process (Cooremans 2012). The main motive for energy-efficiency investments appears to be potential energy cost savings and this motive is consistent with previous research on driving forces for energy-efficiency investments (Brunke et al. 2014; Thollander and Ottosson 2008). During the case study, the communicative value of improving energy efficiency was stressed as an important motive both on group level and by interviewees at the mill. Reducing emissions or becoming fossil free were also mentioned motives; the case investment studied in Paper III was for example initiated due to an identified need to reduce emissions due to environmental compliance. It was thus initiated due to regulations and is therefore an example of an investment not initiated close to production.

The lack of an investment category for investments in energy efficiency was evident both in Paper II and Paper III, which also is indicated in previous studies (Cooremans 2012). However, since energy-efficiency investments often are closely connected to other aims (e.g. Thollander and Ottosson 2010) this should not be a surprising result. Even though six firms in the interview study stated to have a category for energy-efficiency investments, three of these firms also stressed the difficulties for an investment to be adopted on the basis of energy cost savings alone. The case firm P\&P had implemented pure energy-efficiency investments but also stressed that it in most cases were combinatorial investments. However, it should be noted that investments in general were of a combinatorial nature and it was thus not a characteristic specific for energy-efficiency investments. How an energy-efficiency investment was categorised depended on the motive behind it and its combinatorial aim. The effect of investment categorisation on the subsequent process as suggested previously (Cooremans 2012) was indicated in Paper II in which necessary investments in replacements and maintenance had a smoother investment process. However, in Paper III the importance of maintaining availability was emphasised and had a higher priority, yet all investment categories followed the same investment process. Instead the results of Paper III, which placed more emphasis on the investment process than the study in Paper II, indicated that the size of the investment had a strong influence on the subsequent investment process. These mixed findings indicate that investment motive influences the priority of the investment (which takes place during the end of the selection phase), but not necessarily the investment process per se.

\subsubsection{Development and selection}

The two phases development and selection appeared as closely interrelated, as also suggested by Mintzberg et al. (1976). The two phases are therefore jointly discussed in this section. The interrelatedness of these two phases can be illustrated by the pilot study and the pre project identified in Paper III. The pilot study belongs to the development phase and results in the selection of an alternative. After this selection, a pre project is started, in which the selected option is investigated in more detail. Hence, it goes back to the development phase. The development phase includes a number of selections, for instance suppliers. The process is thus a 
multistage process which becomes more detailed for each stage (Minzberg et al. 1976). Here a difference has been indicated between small and large investments (Paper III). The degree of procedural rationality, i.e. the extent to which information is collected and assessed (Dean and Sharfman 1993b), was higher for larger investments. For smaller investment projects, the scope of the pre project was smaller and it was rather a matter of making the investment proposal "good enough", indicating a lower degree of procedural rationality for smaller investments.

The selection phase includes evaluation and authorisation (Mintzberg et al. 1976), which also appear to vary depending on the size of the investment. Previous research has indicated frequent use of the PB method and other capital budgeting tools such as NPV and IRR for evaluating investment projects (e.g. Brunke et al. 2014; Harris et al. 2000; Sandahl and Sjögren 2003; Thollander and Ottosson 2008). From the interview study, the PB method appeared as the most commonly used evaluation tool used for energy-efficiency investments and investments in general, usually with a required PB period of three years or less. Nine firms in the interview study ${ }^{16}$, as well as P\&P, applied more than one capital budgeting tool, especially for larger investments.

Economic arguments have been stressed to be of secondary importance for investment decisions (Cooremans 2012), even though they are frequently presented to decision makers (Lumijärvi 1991). One difference between the interview study and the case study is the weight given to profitability and PB period; from the interview study, these two appeared as the most critical factors for adopting an investment, whereas a slightly different picture arose from the case study. For smaller investments, the results were similar to the interview study with a rather high weight attached to profitability measures and PB. For large investments however, other aspects could be of higher priority; for instance, maintaining availability or if the investment was necessary for production, such as the case investment. Also, less quantifiable non-energy benefits were acknowledged to a larger extent for larger investments. This could be due to two reasons; first, since larger investments are characterised by a higher degree of procedural rationality, more resources are devoted to the investment project, enabling more benefits to be acknowledged. Second, large investments may not be driven by profitability. Nevertheless, all investments were required to at least bear their own costs.

Regarding authorisation of investment proposals, a difference with respect to investment size was yet again indicated. Larger investments were subject to stronger corporate control through the investment manual, the use of a firm-specific discount rate and were required to pass different authorisation stages (Mintzberg et al. 1976; Segelod 1996). For smaller investments, the mills were authorised to decide upon which investments that should be adopted or not. In Paper II, an upper threshold for when investment proposals required authorisation from a higher level was stated, further indicating a presence of investment control as in the case study (e.g. Segelod 1996).

Due to budget restrictions, authorisation includes prioritising between investment projects. Despite the potential cost savings associated with energy-efficiency investments, the fact that energy-efficiency investments are perceived to mainly result in cost savings appears to also hamper these investments. This was elaborated in Paper III; even though energy-efficiency investments are considered important, they have low priority against other investments due to the emphasis on cost savings only. Hence, there appears to be a cost-savings paradox associated with energy-efficiency investments: energy-efficiency investments are both driven and hampered by the energy cost savings motive. In Paper II, profitability and PB were emphasised and it was rather the 'money aspect' behind energy efficiency that was important, and not saving energy, which further strengthens the paradox.

\footnotetext{
16 Including responses from interviews and questionnaire.
} 
It has been suggested that a lack of a link to core business and a low strategic character of energy-efficiency investments could explain why these are not prioritised to a larger extent (Cooremans 2012, 2011; Sandberg and Söderström 2003) and this could in turn explain the apparent cost-savings paradox. However, the empirical results in this thesis, especially from the case study in Paper III, indicate that energy efficiency is considered strategically important due to energy being a large variable cost and an important resource. Energy efficiency is thus strategic in terms of being important (Mintzberg et al. 1976) for the firms' health and survival (Eisenhardt and Zbaracki 1992). Another possible explanation is instead the optional character of energy-efficiency investments as noted by Venmans (2014): even though energy was considered as part of core business ${ }^{17}$, i.e. strategic, other compulsory investment projects were prioritised within a limited investment budget. These findings are in line with those presented in Paper III: investments to for instance maintain availability in production or ensure safety of employees are highly prioritised. Energy-efficiency investments are mainly driven by their potential energy cost savings, which may be substantial yet not compulsory.

\subsubsection{A synthesis of the investment process}

The findings discussed above can be summarised as below in Figure 3, applying the terminology from Mintzberg et al. (1976). The investment process starts with identification and proceeds to development and selection. These two phases are closely related, illustrated by the arrows. If the selection phase results in an acceptance of the investment project, it proceeds to the implementation phase (Cooremans 2012). Based on the findings discussed above, key aspects of these phases can be identified. For the identification phase, this is motives since this is the root for the initiation of the investment process. The primary motive with energy-efficiency investments is potential cost savings, yet there can be other motives such as becoming fossil free in production. Energy-efficiency investments are usually of a combinatorial nature with improving energy efficiency only as one of the aims.

For the two phases development and selection, three key aspects occurs: information, internal coordination and external actors. The investment manual plays a vital role, both in terms of what should be included in the investment application, i.e. information, and how the decision-making process should proceed, i.e. internal coordination (Segelod 1997, 1996). The investment manual includes information on for instance the results of NPV and PB calculations and arguments for making the investments (Lumijärvi 1994). In addition to the importance of the investment manual, the level of procedural rationality, i.e. the extent to which information is collected and analysed before making the decision (Dean and Sharfman 1993b) should be addressed in relation to information. Larger investments passes through a process characterised by a higher degree of procedural rationality than smaller investments, for which it is rather a matter of making the investment application "good enough".

The size of the investment also determines the way in which an investment application is evaluated and eventually selected. Larger investments require authorisation on higher organisational levels and this is as mentioned above stated in an investment manual. In addition to the pre-determined authorisation route established through the investment manual, internal coordination also includes how priorities are set between different investment proposals. Budget restrictions imply that other investments, for instance to ensure availability in production, receives higher priority even though energy efficiency is considered strategically important. The procedure of prioritising between investment needs and applications take place through different committees and boards, depending on the size of the investment.

The last aspect that should be mentioned is external actors, and especially the role of the supplier. The suppliers are highly involved in the investment process, from an early stage. The customers are on the other hand rarely involved during the process but the perspectives of the

17 The study included firms within the ceramic, cement and lime sectors. 
customers were mentioned as possible motives behind the investments, such as becoming fossil free.

The four concepts constituting the decision-making process according to Cyert and March (1963) appear as underlying concepts in the process described above. Quasi resolution of conflict, i.e. the latent conflict of different goals within the organisation, is present in the identification, development and selection phases, for instance in making investment priorities in the selection phase. The concept of uncertainty avoidance is clearly illustrated by the applied requirements in for example $\mathrm{PB}$ time, the higher degree of procedural rationality for larger investments and the weight given to the investment manual (Segelod 1996), i.e. during the phases of development and selection. The third concept, problemistic search, is as already mentioned essential in the identification phase. However, it is also present in the development and selection phases since: "So long as the problem is not solved, search will continue. The problem is solved either by discovering an alternative that satisfies the goals or by revising the goals to levels that are acceptable." (Cyert and March 1963, p. 121). The interrelatedness between the development phase and the selection phase (Mintzberg et al. 1976) as illustrated by the pilot study and pre project in Paper III is an example of this; the search element is present until an investment is accepted and implemented. The fourth and final concept, organisational learning, considers the adaptive behaviour over time and concerns adaptation of goals and rules for evaluation and search (Cyert and March 1963). This has not been studied explicitly in this thesis, yet it is present as a latent concept during the process described above.

Phases of the investment process

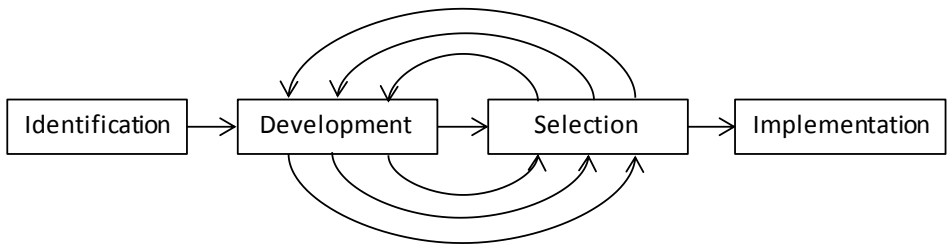

Motives

Cost savings, sustainabilty related or due to regulation. Combinatorial investments.
Information

Investment manual plays a vital role. Large investments: High degree of procedural rationality.

Small investments: "Good enough" and emphasis on profitability measures

Internal coordination

Follows pre-determined authorisation route. Investment priorities and selections are made through for instance the management board, steering committees and investment committees.

External actors

Suppliers highly involved during the investment process.

Figure 3. The phases (based on Mintzberg et al. 1976 and Cooremans 2012) and key aspects of the investment process. 
From the discussion above, it appears that the results differ to a certain extent between the interview study and the case study. Therefore, addressing different perspectives within the organisation and having a process perspective is important when studying investment decision making. Previous research has for instance indicated that managers with different roles have different views on energy efficiency (Cooremans 2012) and on which arguments are important (Lumijärvi 1991). Except for the different roles of the participants in the interview study and the case study, the process perspective is more profound in the case study. While the interview study also has a process perspective towards investment decision making, one of its research questions concerns the critical factors for adopting energy-efficiency investments, which could be interpreted as a choice-based approach (Dean and Sharman 1993a). The more nuanced view on the investment process presented from the case study in Paper III implies that the processoriented approach (e.g. Cyert and March 1963; Dean and Sharfman 1993a) provides new and deeper insights on the investment process for capital investments improving energy efficiency.

\subsection{Non-energy benefits}

In Paper I, a systematic review was conducted of the different benefit concepts used in the literature together with a review of the literature on investment behaviour of energy-efficiency investments. From the combined review, it could be concluded that 'Non-energy benefits' was the most adequate concept to use in an industrial context (Suggestion 1, Paper I). This concept was therefore applied in the remaining research constituting the thesis.

Previous research has emphasised the potential of non-energy benefits for energy-efficiency investments, based on ex-post analysis (Lilly and Pearson 1999; Lung et al. 2005; Pye and McKane 2000; Worrell et al. 2003). In this thesis, another approach has been taken and the thesis has sought to explore the extent to which firms consider non-energy benefits before making the investments and how non-energy benefits should be defined and acknowledged in the investment process. Non-energy benefits have been described as attributes that should be taken into account when classifying energy-efficiency investments (Fleiter et al. 2012; Trianni et al. 2014), stressing the need for an ex-ante perspective.

\subsubsection{To what extent are non-energy benefits acknowledged?}

As displayed in Figure 2 of Paper II, the firms participating in the study had observed several non-energy benefits, although few were monetised. P\&P, the case firm in Paper III, also claimed to have experienced several non-energy benefits. Both in Paper II and Paper III, non-energy benefits could be expressed in terms of costs and revenues. For instance, the most common nonenergy benefits in Paper II were reduced costs for maintenance and operations, while for example the non-energy benefit increased production resulted in revenues.

From the case study at P\&P, the size of the investment appeared to be crucial for the extent to which non-energy benefits are acknowledged during the investment process. As described above, the degree of procedural rationality for the investment process (Dean and Sharfman 1993b) was higher for larger investments, which implied that non-energy benefits to a larger extent were acknowledged during the investment process when larger investments were concerned. When non-energy benefits were acknowledged, it took place during the pre project and in the investment application. The investment manual therefore plays a vital role (Segelod $1997,1996)$ for acknowledging non-energy benefits during the investment process.

For smaller investments, emphasis was placed on making the investment proposal "good enough", which had the implication that less resources were devoted to the pre project. This in turn implied that non-energy benefits were not considered to the same extent for smaller investments. In the meantime, from Paper III smaller investments appeared to be subject to stricter profitability requirements, such as shorter PB periods, and from Paper II profitability and a short PB period appeared as the most critical factors for adopting energy-efficiency investments. Since previous findings have indicated that the inclusion of non-energy benefits 
leads to shorter PB periods (e.g. Worrell et al. 2003), acknowledging quantifiable non-energy benefits should be considered as even more important for smaller energy-efficiency investments. However, both in Paper II and Paper III, the results indicated that quantifiable and non-quantifiable non-energy benefits were considered for energy-efficiency investments. When non-energy benefits could not be quantified and expressed in monetary terms, they were included as comments or in different appendices. Hence, even though monetary information carried a certain weight, both quantifiable and less quantifiable non-energy benefits are considered important by the firms.

Depending on the size of the investment, it needs to pass different authorisation stages. The control and principles established through the investment manual (Segelod 1997, 1996) have implied requirements on simplicity and clarity in the investment applications. A request for using SMART-format when expressing investment goals in the investment application is another example of the requirements of simplicity and clarity (Paper III). From the case study at P\&P, the results indicated a need for emphasis on main effects, rather than on all possible effects. For non-energy benefits, this has the implication that not all possible benefits are or can be acknowledged during the investment process, only the main benefits. Other benefits are observed during implementation.

Both from Paper II and Paper III, the findings indicate that energy-efficiency investments usually come with more than one aim. An example of this is the case investment discussed in Paper III, for which the main aim was to reduce dust emissions, even though improving energy efficiency still was an important underlying factor. Especially in the case study, it was expressed by the participants that non-energy benefits could be the aim and they were therefore not considered as a type of additional benefits. The implication of this is discussed further in section 5.3.

\subsubsection{How should non-energy benefits be defined and acknowledged?}

As a result of the literature review in Paper I, non-energy benefits could be defined as the benefit concept most adequate to use in an industrial context (Suggestion 1), based on the research area and the societal levels on which this concept is usually applied (firm and sectoral) and the type of benefits usually included in the concept, for example reduced maintenance. A matrix was developed in which non-energy benefits could be defined and categorised depending on their level of quantifiability and when in time the benefit is expected to occur (Figure 2, Paper I). The matrix is suggested to be used as a framework for analysing potential non-energy benefits and facilitate their inclusion in the investment process. The potential of non-energy benefits has been emphasised previously (e.g. Pye and McKane 2000), which is why such a framework could function as an important means for including non-energy benefits and making a more accurate assessment of the investment project.

The characteristics of the matrix were addressed empirically in both Paper II and Paper III. In Paper II, the dimension of cost and revenues was added to non-energy benefits. However, with a few exceptions, energy-efficiency investments mainly result in cost savings, consistent with previous literature (Bunse et al. 2009). It was also possible to observe a difference between socalled direct and indirect benefits, of which direct benefits were easily measured but indirect benefits could only be measured indirectly through other benefits. This also implied a difference in when in time these benefits could be measured. On the basis of these results, together with observed results on the quantifiability level of different benefits, a suggested categorisation of the observed non-energy benefits in Paper II could be made, enabling an empirical application of the matrix suggested in Paper I. However, during the case study constituting Paper III, the findings indicated that it was difficult to address the time perspective in that context. With a few exceptions, such as improved public image and work environment, the results indicated that non-energy benefits were realised shortly after implementation, i.e., in a short-term perspective. 
These findings indicate that there may be difficulties in drawing general conclusions on nonenergy benefits, possibly due to the heterogeneity of industries and firms. However, even though different non-energy benefits had been observed and were considered important, there appears to be an emphasis on quantifiable non-energy benefits. As pointed out previously, expressing non-energy benefits in monetary terms improves the business case for energy-efficiency investments (Pye and McKane 2000) and improves their relative advantage (Fleiter et al. 2012). Therefore, the level of quantifiability is important to consider when analysing non-energy benefits. As suggested in Paper I (Suggestion 2), including quantifiable non-energy benefits in the investment evaluation may increase the priority level for energy-efficiency investments and this was also observed in Paper II and Paper III. Del Río González (2005) mentioned an asymmetry between the timing of costs and benefits of clean technologies, and the issue of timing of different additional benefits have been addressed in other fields of research as well (e.g. Grundy and Johnson 1993; Peppard and Ward 2005). The time perspective should therefore be addressed when applicable. In Paper I it was also suggested that non-energy benefits of a low quantifiability could be included at a later step in the investment process (Suggestion 3), but this was not supported by the empirical findings. Rather, an inclusion of non-energy benefits in the investment process should take place as early as possible, regardless of quantifiability level.

Finally, Suggestion 4 in Paper I proposes that non-energy benefits can work as a means to counteract barriers as well as to reinforce driving forces. The potential cost savings have been stressed as the main driver behind energy-efficiency investments, both in previous research (Brunke et al. 2014; Thollander and Ottosson 2008) as well as in Paper II and Paper III. The empirical findings from Paper III and especially Paper II also indicated that most non-energy benefits can be expressed as cost savings, which then can strengthen the case for energyefficiency investments. However, in light of the cost-savings paradox indicated for energyefficiency investments, other characteristics of non-energy benefits could be necessary to address as well. In Paper II, motives related to production were mentioned. In Paper III, aspects such as availability, reduced emissions, production, improved work environment and public image were mentioned as important non-energy benefits that also serves as motives behind energy-efficiency investments. Some of these were also mentioned to be strategically important. Therefore, when there are potential non-energy benefits related to these prioritised issues, they should be emphasised even more, including non-energy benefits that may be difficult to quantify. Non-energy benefits can thus be used as economic, non-economic and strategic arguments (Lumijärvi 1991) for energy-efficiency investments and counteract barriers as well as be in line with the driving forces (Suggestion 4).

The empirical studies in Paper II and Paper III can thus both support and dismiss the suggestions from Paper I. More specifically, Suggestion 1, Suggestion 2 and Suggestion 4 can be supported or partly supported by the results in Paper II and Paper III. Suggestion 3, "non-energy benefits of a low quantifiability level, especially those of a strategic character, can provide additional support at a later step in the decision-making process to select between similar investment opportunities", should however be revised based on the results of Paper III. If nonenergy benefits should be incorporated in the investment process, it should be as early as possible. Moreover, a fifth suggestion is added to illuminate that emphasis should be placed on the main non-energy benefits since there are requirements of simplicity and clarity, for instance by a strict use of an investment manual (Paper III). This is summarised in Table 13 below. 
Table 13. Suggestions on how to define and acknowledge non-energy benefits in the investment process.

\section{Suggestion}

$1 \quad$ Non-energy benefits is the most adequate benefit concept to use in an industrial context (Paper I). Non-energy benefits can be defined by level of quantifiability (supported in Paper II and Paper III) and time frame (partly supported in Paper II and Paper III).

2 Non-energy benefits should be described in quantitative terms to the extent possible since it will improve the business case for energy-efficiency investments and in turn increase the priority (suggested in Paper I, supported in Paper II and Paper III).

3 Non-energy benefits should be included as early as possible in the investment process, regardless of quantifiability level. If necessary, they should be described in words (revised from Paper I based on the results in Paper III).

In particular, emphasis should be placed on non-energy benefits related to prioritised issues to increase the priority level of energy-efficiency investments and avoid the apparent cost-savings paradox (Paper III). Non-energy benefits can thereby work as a means to counteract barriers as well as reinforcing driving forces (suggested in Paper I).

Focus should be on a limited number of main non-energy benefits to comply with the requirements of simplicity and clarity and due to the importance of the investment manual (based on Paper III).

Non-energy benefits of a high level of quantifiability as well as non-energy benefits of a lower quantifiability level should be acknowledged in the investment process. This should take place as early as possible for the benefits to be accounted for in the investment analysis and evaluation. Especially non-energy benefits of a high quantifiability level could contribute to improve the business case, for instance through a shorter PB time (e.g. Worrell et al. 2003). Previous research has indicated that intangible benefits may be tangible in a longer time frame (Grundy and Johnson 1993), which also was indicated for non-energy benefits related to improved work environment (Paper III) and by the presence of indirect benefits (Paper II). The time perspective should therefore be considered when possible. Benefits not possible to quantify should still be included in order not to underestimate the investment's potential (Ashford et al. 1988). Non-energy benefits related to prioritised issues should be emphasised, regardless of their quantifiability level, since it may lead to a higher priority level for energy-efficiency investments and strengthen their relative advantage (Fleiter et al. 2012). Since energy-efficiency investments are considered to mainly lead to energy cost savings, resulting in a cost-savings paradox (Paper III), acknowledging these benefits becomes increasingly important. Finally, it was indicated in Paper III that not all potential benefits can be acknowledged in an investment proposal:

"You cannot include everything every time; you have to save something for the next investment." Investment Manager Strategic Projects (Paper III)

A need for simplicity and clarity in the investment proposal was also stressed by the interviewees at P\&P, especially for larger investments which required authorisation on group level. In the meantime, the findings in Paper III also indicated a higher degree of procedural rationality for larger investments. Since this means that information is collected and analysed to a larger extent for these investments (Dean and Sharfman 1993b), it could be interpreted as an indication that non-energy benefits to a larger extent should be acknowledged for larger investments. However, due to the requirements on the framing of the investment proposal, such 
an interpretation would be inappropriate. The way in which the level of procedural rationality increases for larger investments suggests that there may be more room for taking non-energy benefits into account for larger investments than for smaller investments; yet, emphasis on the main benefits is required.

\subsection{Combinatorial energy-efficiency investments and non-energy benefits - a remark}

Previous research as well as the research conducted within this thesis has indicated energyefficiency investments to usually not be single-aimed investments; they are usually combined with motives related to for instance production (e.g. Pye and McKane 2000; Paper III; Paper II). Investments with the sole aim of improving energy efficiency, in this thesis referred to as pure energy-efficiency investments, are performed but the standard investment has combinatorial aims. However, non-energy benefits are yet relevant to address; even if an energy-efficiency measure is only one part of an investment, it can still yield non-energy benefits, for instance reduced emissions.

For certain non-energy benefits, this view might be somewhat problematic. Non-energy benefits are described as benefits stemming from energy-efficiency investments, other than the energy cost savings (e.g. Worrell et al. 2003). Since the main aim of energy-efficiency investments is to reach energy cost savings, non-energy benefits should be considered as additional benefits. For a number of non-energy benefits, such as improved work environment, reduced maintenance costs, longer lifetime of equipment or reduced emissions, this assumption still holds. However, aspects such as increased production, capacity or availability are the main priorities at an industrial firm and often the main aim of an investment that includes the aim of improving energy efficiency. In this case, these "non-energy benefits" could not be considered as additional benefits. Rather, for investments aiming to improve these aspects, it is energy efficiency that is the additional benefit, and not the other way around. This reversed view on energy efficiency and non-energy benefits implies a need for a perhaps more nuanced perspective on the potential of non-energy benefits. 


\section{Conclusions and suggestions for future research}

In this last chapter, the conclusions will be discussed together with the thesis's contributions, followed last by suggestions for future research.

\subsection{Conclusions}

This thesis took its point of departure from the importance of capital investment decisions for firms operating subject to limited available resources (e.g. Lumijärvi 1991; Maritan 2001). The thesis has taken a process-oriented approach towards investment decision making (Cyert and March 1963) and studied investment decision making at firms within Swedish manufacturing industry. In light of the persisting energy-efficiency gap (e.g. Jaffe and Stavins 1994a; Paramonova et al. 2015), the industry's dependency on energy as a resource (SEA 2015) and a growing investment need in energy efficiency (IEA 2014b) investment decision making has in this thesis been studied by addressing the case of capital investments improving energy efficiency, i.e. energy-efficiency investments. The thesis has also aimed to illuminate how additional benefits, i.e. non-energy benefits, are and should be acknowledged in the investment process. This has enabled conclusions that contribute with insights on the investment process for industrial capital investments in general and industrial energy-efficiency investments in particular.

The results indicate an investment process consistent with the general decision-making process proposed by Mintzberg et al. (1976), which can be described in terms of the phases identification, development and selection, of which the latter two are closely interrelated. The four concepts proposed by Cyert and March (1963) appear as underlying concepts in the process. Moreover, four key aspects related to the three phases have been identified: Motives, information, internal coordination and external actors. Energy-efficiency investments are primarily motivated by their potential energy cost savings, although other motives, such as reducing emissions, were indicated. For larger investments, more resources are devoted to collecting and assess information during the investment process, i.e. larger investments are characterised by a higher degree of procedural rationality. Internal coordination and the authorisation route for investment applications also appeared as dependent on investment size. Further on, the investment manual showed to play a vital role, both in terms of which information that should be presented and how an investment project and its application should be coordinated internally. Regarding external actors, it is indicated that suppliers are highly involved at an early stage in the investment process.

The cost-savings motive behind energy-efficiency investments was emphasised in both empirical studies of the thesis and has previously been identified as a driving force (e.g. Brunke et al. 2014). However, the findings of Paper III indicated that energy-efficiency investments are both driven and hampered by their potential cost savings, suggesting the presence of a costsavings paradox for energy-efficiency investments. Other investments of a compulsory nature, 
such as investments to ensure availability in production or investments related to safety, have higher priority compared to energy-efficiency investments (Venmans 2014); energy-efficiency investments are considered to be "just money"-investments (Paper III).

Except for investment motive, these characteristics of the investment process are not specific for energy-efficiency investments; all investments follow the same investment process, regardless of investment category. On the contrary to previous findings (Cooremans 2012), it is indicated from the findings presented in this thesis that it is investment size rather than category that influences the subsequent investment process, since the size of the investment determines both the level of procedural rationality and the way in which the investment project is coordinated internally. The findings on the investment process, especially from Paper III, also indicated that most investments are of a combinatorial nature, i.e. they are initiated due to a combination of motives, which can include improving energy efficiency. This also implies that an investment may belong to more than one investment category.

A second aim of the thesis was to illuminate additional benefits, i.e. non-energy benefits in the energy-efficiency context, and the thesis has sought to address the extent to which these are acknowledged by firms during the investment process as well as how they should be defined and acknowledged. This ex-ante perspective provides new knowledge insights on non-energy benefits since previous research has focused on reported non-energy benefits, i.e., on ex-post analysis (e.g. Lung et al. 2005; Pye and McKane 2000; Worrell et al. 2003). First, the results of this thesis suggest that in an industrial context, the concept non-energy benefits is the most adequate concept to apply when addressing additional benefits. Non-energy benefits should in turn be defined according to their level of quantifiability and when in time they are expected to occur.

The results indicate that several non-energy benefits are observed and are to a varying extent included in the investment process by the firms studied in this thesis. Non-energy benefits are to a larger extent included for large investments for which more resources are devoted to the investment process; for small investments, it is rather a matter of making the investment proposal "good enough". The results also suggest that non-energy benefits can be considered as economic, non-economic and strategic arguments (Lumijärvi 1991). Quantifiable non-energy benefits are included as economic arguments in the investment evaluation, while non-energy benefits characterised by a low level of quantifiability are included as comments. Certain nonenergy benefits, such as improved public image, can be considered as strategic. An additional aspect to consider in this regard is that even though the participating firms stated that anything that can strengthen the investment case would be useful, it was also stressed that all possible benefits cannot be included every time. There are requirements on maintaining a level of simplicity and clarity in the investment application, as also is indicated by the importance of the investment manual. This leads to the conclusions of research question $3 \mathrm{~b}$ - how non-energy benefits should be acknowledged in the investment process.

Based on the results of this thesis, it is suggested that non-energy benefits are expressed in quantitative terms to the extent possible, in order to improve the profitability of the investment. However, regardless of quantifiability level non-energy benefits should be addressed as early as possible in the investment process. The time perspective, i.e. when in time a benefit is expected to occur, appeared to not always be applicable. Still, when applicable, the time perspective should be addressed since it can improve the accuracy as well as indicate possible long-term benefits of the investment. In addition, even though most non-energy benefits result in cost savings, there are benefits which yield revenues. This dimension should therefore also be considered when describing non-energy benefits.

The indicated difference in investment behaviour with respect to investment size provides implications for how to acknowledge non-energy benefits in the investment process. The 
indication of a higher degree of procedural rationality for larger investments would implicate an investment process in which non-energy benefits could be acknowledged to a larger extent for larger investments. However, since there are requirements on simplicity in the investment manual, emphasis should be placed on the main effects. In light of the identified cost-savings paradox for energy-efficiency investments, it is also important that non-energy benefits related to prioritised issues are emphasised, since this can increase the priority for energy-efficiency investments. This could for instance include non-energy benefits related to production, availability or safety.

Through the conclusions discussed above, the thesis contributes to the literature on energyefficiency investments and non-energy benefits in three ways. First, the interdisciplinary approach of the thesis has contributed with both theoretical and empirical insights on the investment process for energy-efficiency investments and how to acknowledge non-energy benefits. This was enabled by the combination of theory on investment decision making and literature on energy-efficiency investments and non-energy benefits, and by including participants with an energy perspective as well as participants with deeper knowledge on the investment process in general. Second, to the author's best knowledge, only one previous study on energy-efficiency investments (Cooremans 2012) has taken the process perspective applied in this thesis. Further on, this thesis is to the author's best knowledge the first study with such a process perspective focused on the manufacturing industry. This process perspective combined with a focus on the manufacturing industry has enabled deeper insights on investment decision making for energy-efficiency investments. Third, the thesis has contributed with new insights on non-energy benefits by applying an ex-ante perspective on non-energy benefits. The findings of this thesis contributes with new insights on how non-energy benefits should be acknowledged already during the investment process, which in turn can improve the relative advantage for energy-efficiency investments (Fleiter et al. 2012) and contribute to closing the energyefficiency gap.

By addressing investment decision making for the case of energy-efficiency investments and non-energy benefits, the thesis has aimed to add insights on firms' investment decision making for capital investments and how additional benefits are acknowledged in the investment process. Since the investment process is consistent regardless of investment category, the conclusions drawn on the investment process for energy-efficiency investments should be transferable to a discussion on capital investments in general. Previous research outside the scope of energy-efficiency investments has also stressed the need for a frame of reference to enable a broader analysis which could take different benefits into account, both tangible and intangible (e.g. Irani and Love 2002). While both tangible and intangible benefits should be acknowledged (Ashford et al. 1988), the findings of this thesis suggest that there is a limit in the extent to which these additional benefits can be considered in the investment process. There should be an emphasis on main benefits, in particular when there is a dependency on an investment manual and the investment process involves a high level of internal coordination. An investment manual has been indicated to play a vital role in engineering and forest groups (Segelod 1996), which are included both in Paper II and Paper III of this thesis. The conclusions presented in this thesis on how to acknowledge non-energy benefits of energy-efficiency investments would therefore be transferable to the general case, at least for large firms within these industries. The thesis thus contributes with new insights on how to acknowledge additional benefits of capital investments, both quantifiable and less quantifiable.

\subsection{Suggestions for future research}

As described above, the thesis provides new insights on how to acknowledge additional benefits in the investment process. The heterogeneity of industries and firms do however imply certain limitations on how general these recommendations can be. For instance, the time perspective suggested in Paper I was applicable in Paper II but only partly in the case study in Paper III. 
Other differences occurred between Paper II and Paper III, for instance the weight given to profitability and PB time indicated in Paper II. These differences could be attributable to the process perspective, which was more prominent in Paper III. There is thus a need for future research in the manufacturing industry as well as other industries, in which a process perspective is applied to analyse whether these results are limited to this specific case or if they can be found elsewhere.

The results on non-energy benefits suggest that there should be an emphasis on main benefits when these benefits are acknowledged in the investment process. This calls for future research in which main non-energy benefits are assigned to specific energy-efficiency investments, both for small and large investments. The level of quantifiability, time perspective and whether the non-energy benefits result in a reduced costs or increased revenues should then be addressed to facilitate the incorporation of non-energy benefits into the investment process.

Suppliers are highly involved in the investment process from an early stage and their role in the investment process is thus important for energy-efficiency investments. However, the extent to which suppliers of energy-efficiency investments consider non-energy benefits remains unexplored. Customers do not appear to be involved in the investment process. Yet, the perspective of the customers was addressed through motives such as becoming fossil free, which is important for customers interested in conducting a carbon footprint. Non-energy benefits such as improved quality and green public image also address the perspective of the customers. Future research should therefore include both suppliers and customers when studying energyefficiency investments and non-energy benefits.

Last, not all measures to improve energy efficiency take place through investments. Energyefficiency measures not incurring investment expenditure needs to be included, especially in light of the extended energy-efficiency gap in which the potential from energy management practices also is acknowledged (Backlund et al. 2012). This advocates future research on energy management systems and other aspects which put emphasis on the operational work with energy efficiency. 


\section{References}

Aboelela, S. W., Larson, E., Bakken, S., Carrasquillo, O., Formicola, A., Glied, S. A., Haas, J., Gebbie, K. M. (2007). Defining Interdisciplinary Research: Conclusions from a Critical Review of the Literature. HSR: Health Services Research (1): 329-346

Alkaraan, F. and Northcott, D. (2006). Strategic capital investment decision-making: A role for emergent analysis tools? A study of practice in large UK manufacturing companies. The British Accounting Review 38: 149-173

Alvesson, M. (2003). Beyond Neopositivists, Romantics, and Localists: A Reflexive Approach to Interviews in Organizational Research. The Academy of Management Review 28(1): 1333

Alvesson, M. and Sköldberg, K. (2000). Reflexive Methodology. New Vistas for Qualitative Research. SAGE Publications

Armerin, F. and Song, H-S. (2014). Investeringsbedömningens grunder - från traditionella metoder till realoptioner. Studentlitteratur

Arvanitis, S. and Ley, M. (2013). Factors Determining the Adoption of Energy-Saving Technologies in Swiss Firms: An Analysis Based on Micro Data. Environmental Resource Economics. 54: 389-417

Ashford, R. W., Dyson, R. G., Hodges, S. D. (1988). The Capital-Investment Appraisal of New Technology: Problems, Misconceptions and Research Directions. Journal of the Operational Research Society 39(7):637-642

Ayres, L., Kavanaugh, K., Knafl, K. A. (2003). Within-Case and Across-Case Approaches to Qualitative Data Analysis. Qualitative Health Research 13(6): 871-883

Backlund, S., Thollander, P., Palm, J., Ottosson, M. (2012). Extending the energy efficiency gap. Energy Policy 51: 392-396

Baxter, J. A. and Chua, W. F. (1998). Doing Field Research: Practice and Meta-Theory in Counterpoint. Journal of Management Accounting Research 10: 69-87

Baxter, P. and Jack, S. (2008). Qualitative Case Study Methodology: Study Design and Implementation for Novice Researchers. The Qualitative Report 13(4): 544-559

Bennouna, K., Meredith, G. G., Marchant, T. (2010). Improved capital budgeting decision making: evidence from Canada. Management Decision 48(2): 225-247

Bierman, H. Jr. and Smidt, S. (2012). The Capital Budgeting Decision. Economic analysis of investment projects. $9^{\text {th }}$ ed., Routledge Taylor \& Francis Group

Bourgeois, L. J. III and Eisenhardt, K. M. (1988I. Strategic Decision Processes in High Velocity Environments: Four Cases in the Microcomputer Industry. Management Science 34(7): 816-835

Bower, J. L. (1986). Managing the Resource Allocation Process. Harvard Business School Press Books

Boyd, G. A. and J. X. Pang (2000). Estimating the linkage between energy efficiency and productivity. Energy Policy, 28(5), 289-296

Brealey, R. A., Myers, S. C., Allen, F. (2011). Principles of Corporate Finance. 10 ${ }^{\text {th }}$ ed. McGraw-Hill

Brunke, J-C., Johansson, M., Thollander, P. (2014). Empirical investigation of barriers and drivers to the adoption of energy conservation measures, energy management practices and energy services in the Swedish iron and steel industry. Journal of Cleaner Production 84: 509-525

Bryman, A. and Bell, E. (2011). Business Research Methods, $3^{\text {rd }}$ ed. Oxford University Press

Bunse, K., Sachs, J., Vodicka, M. (2009) Evaluating Energy Efficiency Improvements in Manufacturing Processes, in Vallespir, B. and Alix, T., Advances in Production Management Systems, IFIP AICT 338: 19-26

Butler, R., Davies, L., Pike, R., Sharp, J. (1991). Strategic investment decision-making: Complexities, politics and processes. Journal of Management Studies 28(4): 395-415

Cagno, E. and Trianni, A. (2014). Evaluating the barriers to specific industrial energy efficiency measures: an exploratory study in small and medium-sized enterprises. Journal of Cleaner Production 82: 70-83 
Cagno, E., Worrell, E., Trianni, A., Pugliese, G. (2013). A novel approach for barriers to energy efficiency. Renewable and Sustainable Energy Reviews 19: 290-308

Cho, J. and Trent, A. (2006). Validity in qualitative research revisited. Qualitative Research 6(3): 319-340. SAGE Publications

Collins, J. A. and Fauser, B. C. J. M. (2005). Balancing the strengths of systematic and narrative reviews. Human Reproduction Update 11(2): 103-104

Cooremans, C. (2011). Make it strategic! Financial investment logic is not enough. Energy Efficiency, 4(4), 473-492

Cooremans, C. (2012). Investments in energy efficiency: do the characteristics of investments matter? Energy Efficiency 5:497-518

Creswell, J. W. (2003). Research design: Qualitative, Quantitative, and Mixed Methods Approaches. 2nd ed., SAGE Publications, California

Creswell, J. W. and Miller, D. L. (2000). Determining Validity in Qualitative Inquiry. Theory into Practice 39(3): 124-130

Cyert, R. M. and March, J. G. (1963). A behavioral theory of the firm. Prentice-Hall Inc, Englewood Cliffs New Jersey

Dean, J. W. and Sharfman, M. P. (1993a). The Relationship between Procedural Rationality and Political Behavior in Strategic Decision Making. Decision Sciences 24(6): 1069-1083

Dean, J. W. and Sharfman, M. P. (1993b). Procedural rationality in the strategic decision-making process. Journal of Management Studies 30(4): 587-610

DeCanio, S. J. (1998). The efficiency paradox: bureaucratic and organizational barriers to profitable energy-saving investments. Energy Policy 26(5): 441-454

DeCanio, S. J. (1993). Barriers within firms to energy-efficient investments. Energy Policy 9(1): 906-914

DeCanio, S. J. and Watkins, W. E. (1998). Investments in energy efficiency: do the characteristics of firms matters? Review of Economics and Statistics 80(1): 95-107

De Groot, H. L. F., Verhoef, E. T., Nijkamp, P. (2001). Energy saving by firms: Decision-making, barriers and policies. Energy Economics, 23(6), 717-740

Del Río González, P. (2005). Analysing the Factors Influencing Clean Technology Adoption: A Study of the Spanish Pulp and Paper Industry. Business Strategy and the Environment 14: $20-37$

Dempsey, J., Dvorak, R. E., Holen, E., Mark, D., Mehan III, W. F. (1998). A hard and soft look at IT investments. The McKinsey Quarterly 1: 126-137

Dijkers, M.P.J.M. (2009). The Task Force on Systematic Reviews and Guidelines: The Value of "Traditional" Reviews in the Era of Systematic Reviewing. Am J Phys Med Rehabil 88: 423-430

Dubois, A. and Gadde, L-E. (2002). Systematic combining: an abductive approach to case research. Journal of Business Research 55:553-560

Eccles, R. G., Ioannou, I., Serafeim, G. (2014). The Impact of Corporate Sustainability on Organizational Processes and Performance. Management Science 60(11): 2835-2857. Retrieved 20151124 through Digital Access to Scholarship at Harvard (DASH), https://dash.harvard.edu/handle/1/15788003

Eisenberg, R. S. (1988). Academic Freedom and Academic Values in Sponsored Research. Texas Law Review 66: 1363-1404

Eisenhardt, K. M. (1989a). Making Fast Strategic Decisions in High-Velocity Environments. Academy of Management 32(3): 543-576

Eisenhardt, K. M. (1989b). Building Theories from Case Study Research. The Academy of Management Review 14(4): 532-550

Eisenhardt, K. M. and Zbaracki, M. J. (1992). Strategic Decision Making. Strategic Management Journal 13: 17-37

Emmanuel, C., Harris, E., Komakech, S. (2010). Towards a better understanding of capital investment decisions. Journal of Accounting and Organizational Change 6(4): 477-504

Eurostat (2014). http://ec.europa.eu/eurostat/statisticsexplained/index.php/Glossary:Enterprise_size Retrieved 20151123 
Fleiter, T., Hirzel, S., Worrell, E. (2012). The characteristics of energy-efficiency measures - a neglected dimension. Energy Policy 51: 501-513

Flyvbjerg, B. (2006). Five Misunderstandings About Case-Study Research. Qualitative Inquiry 12(2): 219-265

Graham, J. R. and Harvey, C. R. (2001). The theory and practice of corporate finance: evidence from the field. Journal of Financial Economics 60: 187-243

Grundy, T. and Johnson, G. (1993). Managers' Perspectives on Making Major Investment Decisions: the Problem of Linking Strategic and Financial Appraisal. British Journal of Management 4: 253-267

Guba, E. G. (1981). Criteria for Assessing the Trustworthiness of Naturalistic Inquires. Educational Communication and Technology 29(2): 75-91

Guenther, K. M. (2009). The politics of names: rethinking the methodological and ethical significance of naming people, organizations, and places. Qualitative Research 9(4): 411-421

Hall, N. P. and Roth, J. A. (2003). Non-energy benefits from commercial and industrial energy efficiency programs: Energy efficiency may not be the best story. Energy Program Evaluation conference Seattle: 689-702

Hammersley, M. (2002). Systematic or Unsystematic, is that the Question? Some reflections on the science, art, and politics of reviewing research evidence. Text of talk given to the Public Health Evidence Steering Group of the Health Development Agency, October 2002. Accessed through Research Gate: http://www.researchgate.net/profile/Martyn_Hammersley/publication/237416646_S ystematic_or_Unsystematic_is_that_the_Question_Some_reflections_on_the_science_art_ and_politics_of_reviewing_research_evidence/links/53ebb42b0cf202d087ce7579.pdf Retrieved 20150928

Harris, J., Anderson, J., Shafron, W. (2000). Investment in energy efficiency: a survey of Australian firms. Energy Policy 28: 867-876

Hasanbeigi, A., Menke, C., du Pont, P. (2010). Barriers to energy efficiency improvement and decision-making behavior in Thai industry. Energy Efficiency 3: 33-52

Hirst, E. and Brown, M. (1990). Closing the efficiency gap: barriers to the efficient use of energy. Resources, Conservation and Recycling 3: 267-281

Howart, R. B. and Andersson, B. (1993). Market barriers to energy efficiency. Energy Economics 15(4): 262-272

Huutoniemi, K., Thompson Klein, J., Bruun, H., Hukkinen, J. (2010). Analyzing interdisciplinarity : Typology and indicators. Research Policy 39: 79-88

IEA (2014a). Capturing the Multiple Benefits of Energy Efficiency. OECD/IEA, Paris

IEA (2014b). World Energy Investment Outlook. OECD/IEA, Paris

IEA (2012). Spreading the Net: The Multiple Benefits of Energy Efficiency Improvements. Insight Series 2012. OECD/IEA, Paris

Irani, Z. and Love, P. E. D. (2002). Developing a frame of reference for ex-ante IT/IS investment evaluation. European Journal of Information Systems 11: 74-82

Jackson, J. (2010). Promoting energy efficiency investments with risk management decision tools. Energy Policy 38: 3865-3873

Jaffe, A. B. and Stavins, R. N. (1994a). The energy efficiency gap: What does it mean? Energy Policy, 22(10), 804-810

Jaffe, A. B. and Stavins, R. N. (1994b). The energy paradox and the diffusion of conservation technology. Resource and Energy Economics 16:91-122

King, P. (1975). Is the Emphasis of Capital Budgeting Theory Misplaced? Journal of Business Finance \& Accounting 2(1): 69-82

Kvale, S. and Brinkmann, S. (2012). Den kvalitativa forskningsintervjun, $2^{\text {nd }}$ ed. Studentlitteratur

Langley, A., Mintzberg, H., Pitcher, P., Posada, E., Saint-Macary, J. (1995). Opening up Decision Making: The View from the Black Stool. Organization Science 6(3):260-279

Lefley, F. (1996). The payback method for investment appraisal: A review and synthesis. International Journal of Production Economics 44: 207-224 
Lilly, P. and Pearson, D. (1999). Determining the full value of industrial efficiency programs. Proceedings ACEEE Summer Study on Energy Efficiency in Industry: 349-362

Lincoln, Y. S. and Guba, E. G. (1985). Naturalistic Inquiry. SAGE Publications

Lincoln, Y. S. and Guba, E. G. (1986). But Is It Rigorous? Trustworthiness and Authenticity in Naturalistic Evaluation. New Directions for Program Evaluation 30: 15-25

Lumijärvi, O. P. (1991). Selling of capital investments to top management. Management Accounting Research 2: 171-188

Lung, R. B., McKane, A., Leach, R., Marsh, D. (2005) Ancillary savings and production benefits in the evaluation of industrial energy efficiency measures. Proceedings ACEEE Summer Study on Energy Efficiency in Industry: 104-114

Maritan, C. A. (2001). Capital investment as investing in organizational capabilities: an empirically grounded process model. Academy of Management Journal 44(3): 513-531

Martin, R., Muuls, M., de Preux, L. B., Wagner, U. J. (2012). Anatomy of a paradox : Management practices, organizational structure and energy efficiency. Journal of Environmental Economics and Management 63: 208-223

Maxwell, J. (2009). Designing a qualitative study. In Bickman, L. and Rog, D.J. The Sage handbook of applied social research methods, $2^{\text {nd }}$ ed. Thousand Oaks, SAGE

Mills, E., Shamshoian, G., Blazek, M., Naughton, P., Seese, R. S., Tschudi, W., Sartor, D. (2008). The business case for energy management in high-tech industries. Energy Efficiency 1(1): 520

Mintzberg, H., Raisinghani, D., Théoret, A. (1976). The Structure of the "Unstructured" Decision Processes. Administrative Science Quarterly 21(2): 246-275

Namey, E., Guest, G., Thairu, L., Johnson, L. (2008). Data reduction techniques for large qualitative data sets. In Guest, G. and MacQueen, K. M. (Eds.) Handbook for team-based qualitative research. AltaMira Press

Needleman, I. G. (2002). A guide to systematic reviews. Journal of Clinical Periodontology 29(3): 6-9

Nehler, T., Thollander, P., Ottosson, M., Dahlgren, M. (2014). Including non-energy benefits in investment calculations in industry - empirical findings from Sweden. Proceedings ECEEE Industrial Summer Study - Retool for a Competitive and Sustainable Industry 711719

Nutt, P. (1993). The Formulation Process and Tactics Used in Organizational Decision Making. Organizational Science 4(2): 226-251

Paramonova, S., Thollander, P., Ottosson, M. (2015). Quantifying the extended energy efficiency gap - evidence from Swedish electricity-intensive industries. Renewable and Sustainable Energy Reviews 51: 472-483

Patterson, M. G. (1996). What is energy efficiency? Concepts, indicators and methodological issues. Energy Policy 24(5): 377-390

Peppard, J. and Ward, J. (2005). Unlocking sustained business value from IT investment. California Management Review 48(1): 52-70

Porter, M. E. (1985). Competitive Advantage. Free Press, New York

Porter, M. E. (1980) Competitive Strategy. Free Press, New York

Porter, M. E. and van der Linde, C. (1995). Green and Competitive: Ending the Stalemate. Harvard Business Review 73(5): 120-134

Posch, A., Brudermann, T., Braschel, N., Gabriel, M. (2015). Strategic energy management in energy-intensive enterprises: a quantitative analysis of relevant factors in the Austrian paper and pulp industry. Journal of Cleaner Production 90: 291-299

Provan, K. G. (1989). Environment, Department Power, and Strategic Decision Making in Organizations: A Proposed Integration. Journal of Management 15(1): 21-34

Puig, D. and Farrell, T.C. (2015). The multiple benefits of measures to improve energy efficiency. UNEP DTU Partnership. Copenhagen

Pye, M., McKane, A. (2000). Making a stronger case for industrial energy efficiency by quantifying non-energy benefits. Resources, Conservation and Recycling 28:171-183 
Qiu, Y., Wang, Y. D., Wang, J. (2015). Implied discount rate and payback threshold of energy efficiency investment in the industrial sector. Applied Economics 47(21): 2218-2233

Rasmussen, J. (2014). Energy-efficiency investments and the concepts of non-energy benefits and investment behaviour. Proceedings ECEEE Industrial Summer Study - Retool for a Competitive and Sustainable Industry 733-744

Rohdin, P., Thollander, P., Solding, P. (2007). Barriers to and drivers for energy efficiency in the Swedish foundry industry. Energy Policy 35: 672-677

Rohdin, P. and Thollander, P. (2006). Barriers to and driving forces for energy efficiency in the non-energy intensive manufacturing industry in Sweden. Energy 31: 1836-1844

Saldaña, J. The Coding Manual for Qualitative Researchers. SAGE Publications

Sandahl, G. and Sjögren, S. (2003). Capital budgeting methods among Sweden's largest groups of companies. The state of the art and a comparison with earlier studies. International Journal of Production Economics 84: 51-69

Sandberg, P. and Söderström, M. (2003). Industrial energy efficiency: The need for investment decision support from a manager perspective. Energy Policy 31: 1623-1634

Sardianou, E. (2008). Barriers to industrial energy efficiency investments in Greece. Journal of Cleaner Production, 16(13), 1416-1423.

SEA (2015). Energiläget 2015. ET2015:08. Statens energimyndighet

SEA (2014a). https://www.energimyndigheten.se/Foretag/Energieffektivisering-i-foretag/PFE/ Retrieved 20150923

SEA (2014b). https://www.energimyndigheten.se/Foretag/Energieffektivisering-iforetag/energiledning/ Retrieved 20150923

SEA (2014c). https://www.energimyndigheten.se/Foretag/Energieffektivisering-iforetag/energiledning/Certifierade-system/ Retrieved 20150923

SEA (2013). Energiläget 2013. ET 2013:22. Statens energimyndighet

SEA (2012). Energiläget 2012. ET 2012:34. Statens energimyndighet

Segelod, E. (1997). The content and role of the investment manual - a research note. Management Accounting Research 8: 221-231

Segelod, E. (1996). Corporate control of investments and management styles. International Journal of Production Economics 43: 227-237

Sorrell, S., Schleich, J., Scott, S., O’Malley, E., Trace, F., Boede, U., Ostertag, K., Radgen, P. (2000). Reducing barriers to energy efficiency in public and private organizations. Energy research centre - science and technology policy research (SPRU), University of Sussex, Brighton

Stake, R. E. (1995). The Art of Case Study Research. SAGE Publications

Strauss, A. and Corbin, J. (1998). Basics of Qualitative Research, Techniques and Procedures for Developing Grounded Theory, $2^{\text {nd }}$ ed. SAGE Publications

Söderström, M. (1996). Industrial Electricity Use Characterized by Unit Processes: A Tool for Analysis and Forecasting. Proceedings UIE XIII Congress on Electricity Applications, Birmingham: 77-85

Thollander, P. and Ottosson, M. (2008). An energy efficient Swedish pulp and paper industry exploring barriers to and driving forces for cost-effective energy efficiency investments. Energy Efficiency 1:21-34

Thollander, P. and Ottosson, M. (2010). Energy management practices in Swedish energyintensive industries. Journal of Cleaner Production 18: 1125-1133

Tranfield D., Denyer, D., Smart, P. (2003). Towards a Methodology for Developing EvidenceInformed Management Knowledge by Means of Systematic Review. British Journal of Management 14: 207-222

Trianni, A., Cagno, E., De Donatis, A. (2014). A framework to characterize energy efficiency measures. Applied Energy 118: 207-220

Trianni, A., Cagno, E., Thollander, P., Backlund, S. (2013). Barriers to industrial energy efficiency in foundries: a European comparison. Journal of Cleaner Production 40: 161-176

Trianni, A. and Cagno, E. (2012). Dealing with barriers to energy efficiency and SMEs: Some empirical evidences. Energy 37: 494-504 
UNIDO, United Nations Industrial Development Organization. (2011). Industrial Development Report 2011. Industrial energy efficiency for sustainable wealth creation. Capturing environmental, economic and social dividends. UNIDO ID No. : 442

Ürge-Vorsatz, D., Harvey, L. D. D., Mirasgedis, S., Levine, M. D. (2007). Mitigating $\mathrm{CO}_{2}$ emissions from energy use in the world's buildings. Building Research and Information 35(4): 379398

Van Cauwenbergh, A., Durinck, E., Martens, R., Laveren, E., Bogaert, I. (1996). On the role and function of formal analysis in strategic investment decision processes: results from an empirical study in Belgium. Management Accounting Research 7: 169-184

Van Soest, D. P. and Bulte, E. H. (2001). Does the Energy-Efficiency Paradox Exist? Technological Progress and Uncertainty. Environmental and Resource Economics 18: 101-112

Velthuijsen, J. W. (1993). Incentives for Investments in Energy Efficiency: An Econometric Evaluation and Policy Implications. Environmental and Resource Economics 3: 153-169

Venmans, F. (2014). Triggers and barriers to energy efficiency measures in the ceramic, cement and lime sectors. Journal of Cleaner Production 69: 133-142

Webster, J. and Watson, R. T. (2002). Analyzing the Past to Prepare for the Future: Writing a Literature Review. MIS Quarterly 26(2): 13-23

Wickson, F., Carew, A.L., Russell, A.W. (2006). Transdisciplinary research: characteristics, quandaries and qualities. Futures 38: 1046-1059

Whittemore, R., Chase, S. K., Lynn Mandle, C. (2001). Validity in Qualitative Research. Qualitative Health Research 11(4): 522-537

Worrell, E., Laitner, J. A., Ruth, M., Finman, H. (2003). Productivity benefits of industrial energyefficiency measures. Energy 28:1081-1098

Xue, Y., Liang, H., Boulton, W. R. (2008). Information technology governance in information technology investment decision processes: the impact of investment characteristics 0 , external environment, and internal context. MIS Quarterly 32(1): 67-96

Yin, R. K. (2009). Case Study Research Design and Methods, $4^{\text {th }}$ ed. Applied Social Research Methods Series, vol. 5. SAGE Publications

Yin, R. K. (2011). Kvalitativ forskning från start till mål, $1^{\text {st }}$ ed. Translated by Retzlaff, J., prepared by Östbring, B. Original title: Qualitative Research from Start to Finish. Studentlitteratur

Ylijoki, O. H. (2003). Entangled in academic capitalism? A case-study on changing ideals and practices of university research. Higher Education 45: 307-335 


\section{Part II:}

Appended Papers 



\section{Appended Papers}

The articles associated with this thesis have been removed for copyright reasons. For more details about these see:

http://urn.kb.se/resolve?urn=urn:nbn:se:liu:diva-126367 